Revista lus et Praxis, Año 19, № 1, 2013, pp. 255 - 300

ISSN 0717 - 2877

Universidad de Talca - Facultad de Ciencias Jurídicas y Sociales

"Una propuesta de análisis y regulación del aborto en

Chile desde el pensamiento feminista"

Yanira Zúñiga Añazco

\title{
UNA PROPUESTA DE ANÁLISIS Y REGULACIÓN DEL ABORTO EN CHILE DESDE EL PENSAMIENTO FEMINISTA*
}

\author{
A FEMINIST PROPOSAL OF ANALYSIS AND REGULATION \\ OF THE ABORTION IN CHILE
}

\begin{abstract}
YANIRA ZÚÑIGA AÑAZCO**
RESUMEN

Este trabajo analiza la regulación y los debates sobre el aborto desde una teoría feminista y ofrece argumentos para abandonar una lectura constitucional centrada en la personalidad del nasciturus y reemplazarla, en cambio, por un modelo de análisis con base en una concepción situada de la autonomía. Asimismo, contiene una propuesta concreta de enmienda de la legislación chilena con base en esta concepción de autonomía.

\section{ABSTRACT}

This work analyzes the regulation of abortion and its surrounding debates from the perspective of feminist theory, and offers arguments to abandon a constitutional reading thereof centered on the personhood of the fetus in order to replace it with an analytical framework based on a contextually rooted understanding of autonomy. It also proposes a specific amendment to Chilean legislation based on this understanding of autonomy.

Palabras Clave

Aborto, Género, Feminismo

KEYWORDS

Abortion, Gender, Feminism
\end{abstract}

\section{INTRODUCCIÓN}

El aborto es uno de los temas que genera mayor polarización en nuestras sociedades contemporáneas porque supone una verdadera encrucijada de tradiciones éticas y opciones regulativas desde las cuales se aspira a construir

\footnotetext{
* Trabajo recibido el 13 de marzo de 2013 y aprobado el 11 de abril de 2013.

** Doctora en Derecho; Profesora Facultad de Ciencias Jurídicas y Sociales, Universidad Austral de Chile, Instituto de Derecho Público. Dirección postal: Facultad de Ciencias Jurídicas y Sociales, Universidad Austral de Chile, Campus Isla Teja, Valdivia. Correo electrónico: yzuniga@uach.cl. Este trabajo forma parte del proyecto FONDECYT No 1110574 que lleva por título La constitucionalización de la familia. Tendencias del Derecho comparado y desafíos normativos para el Derecho chileno; respecto del cual la autora es investigadora principal.
} 
respuestas universales aplicables a una variada casuística individual y social. En este sentido, los debates sobre el aborto están lejos de ser discusiones que versen únicamente sobre el estatuto moral del nasciturus -como es frecuente escuchar-y son, en cambio, verdaderos test sobre la forma en que las sociedades democráticas equilibran, con pretensiones de justicia, intereses contradictorios, entre otros, la protección de la vida, de la libertad y de la igualdad.

Por lo mismo, el hecho de que la sociedad chilena, a través de sus cuerpos representativos, no se haya tomado la molestia de discutir seriamente esta cuestión desde el término de la dictadura militar, refleja, con mayor nitidez que la ausencia de deliberación en otros temas (como los relativos al sistema electoral), que a la democracia chilena le falta todavía consistencia.

Mi interés aquí es explorar el tratamiento del aborto en clave fundamentalmente teórica, a partir del examen de sus normas regulativas en los ámbitos interno (nacional y comparado) e internacional y de la revisión de los ejes ideológicos que se enfrentan en los debates sobre la mejor forma de enfrentar este tema. Sin embargo, no quiero contentarme -como lo hacen varios trabajos- con ofrecer una lectura general sobre este problema, desprovista de una propuesta jurídica que la materialice. Por el contrario, me gustaría avanzar en la construcción de una propuesta interpretativa o regulativa, en su caso, que sea útil para abordar su tratamiento en Chile.

En consecuencia, sostendré como hipótesis que a efectos de aproximarse adecuadamente a esta cuestión es necesario abandonar el esquema de análisis concentrado en la personalidad del no nato-mayoritario en la doctrina nacionalno sólo porque supone un marco jurídico-conceptual estrecho y reduccionista, de muy discutible encaje constitucional; sino que también porque esta aproximación lleva, necesariamente, a soluciones hipócritas e ineficaces que ni son susceptibles de justificar una limitación intensa de la autonomía procreativa de las mujeres -como la que contempla actualmente la ley chilena a través de la punición general del aborto- ni sirven de base para el desarrollo de políticas adecuadas de protección de la vida emergente. En contrapartida, mi propuesta de análisis parte desde la autonomía, entendida como una autonomía situada, y admite un eventual régimen de restricciones a condición de que satisfaga un test de proporcionalidad compatible con tal modelo.

El itinerario de este trabajo se dividirá en tres partes. La primera (1) destinada a explorar panorámicamente el contexto socio-normativo del aborto, resaltando sus disonancias y contradicciones (1.1 y 1.2), y ofreciendo algunas pistas para decodificarlas en clave de género (1.3). La segunda parte (2) examina críticamente algunos de los argumentos tradicionales que intervienen en las discusiones sobre su regulación, en particular, los que enfrentan a conservadores y liberales (2.1) y revisa críticamente, a la luz del mencionado debate, el estado de la cuestión en Chile (2.2). La tercera parte (3) presta especial atención al 
repertorio conceptual elaborado por la teoría feminista, principalmente a su esfuerzo de construcción de una concepción situada de la autonomía, alternativa al paradigma liberal (3.1), y presenta una cartografía feminista que pueda servir de base para su lectura constitucional y para una eventual reforma de la legislación chilena (3.2).

\section{Panorama normativo sobre el aborto. Entre disonanCias y CONTRADICCIONES}

La regulación jurídica de la interrupción voluntaria del embarazo -que aquí denominaré simplemente aborto-se caracteriza por ser disonante en dos sentidos. Por un lado, lo es desde el punto de vista de las posiciones jurídicas adoptadas por los distintos ordenamientos a nivel comparado e internacional. Y, por otro, en relación con su capacidad efectiva para alcanzar uno de sus objetivos declarados: la protección del no nato. En este segundo nivel la disonancia implica una brecha entre normatividad y eficacia. Ambas disonancias envuelven sus propias contradicciones y problemas. Revisemos cada una de estas dimensiones.

\subsection{La casuística del aborto}

La heterogeneidad de respuestas jurídicas en torno al aborto es llamativa. Existen ordenamientos que prohíben todos o la gran mayoría de los supuestos imaginables de aborto, como ocurre en el caso chileno, mientras que otros lo permiten sin restricción de causales -aunque a veces sometido a régimen de consejo- dentro de un determinado plazo que oscila, en general, entre las 12 y las 24 semanas de gestación, como ocurre en la mayor parte de Europa occidental ${ }^{1}$ y en EE.UU.

En el terreno intermedio se sitúan aquellas legislaciones que lo permiten siempre y cuando concurran determinadas circunstancias. Estas circunstancias se han vinculado ordinariamente a la protección de la vida o salud de la madre, el origen del embarazo (por ejemplo, una violación) y la situación socioeconómica de la madre ${ }^{2}$. A este último sistema se le suele denominar régimen de indicaciones o permisos. No es infrecuente que ambos modelos se hibriden. El sistema alemán, por ejemplo, combina el modelo de plazos y el de indicaciones. Admite el aborto en general durante las primeras 12 semanas y extiende este plazo a 22 semanas cuando existe peligro para la vida de la madre o grave

\footnotetext{
1 Así, por ejemplo, Alemania, Austria, Bélgica, Francia, Dinamarca, España, Grecia, Italia, y Suecia permiten la interrupción voluntaria del embarazo sin justificación, en general, hasta la semana 12, y Holanda hasta la semana 24.

${ }^{2}$ Cabe mencionar que el régimen de indicaciones o permisos ha resultado ampliado en las últimas décadas incorporando otras causales como la adolescencia o la edad avanzada de la madre o la infección por VIH.
} 
lesión a su salud físico-psíquica o cuando el embarazo tiene su origen en una violación.

La disparidad de regulación puede darse también en el marco de un mismo país. La legislación de ciudad de México, permite desde 2007 el aborto en cualquier supuesto, dentro de las primeras 12 semanas del embarazo. En los demás estados mexicanos la regulación es variopinta y regula un régimen más o menos extenso de indicaciones ${ }^{3}$.

Desde una perspectiva estrictamente demográfica, con todo, resulta que en un $40 \%$ de la población mundial la sola demanda de las mujeres basta para que se interrumpa legalmente el embarazo, teniendo en cuenta que los Estados más densamente poblados (China e India), así lo aceptan.

Otra forma de clasificar las regulaciones sobre el aborto es la que propone Rebecca J. Cook. La autora distingue entre regulaciones (o leyes) básicas, desarrolladas, avanzadas y despenalizadoras ${ }^{4}$. Las primeras se caracterizan por contener una prohibición penal amplia del aborto, mientras que las segundas, si bien no difieren de las primeras en su orientación punitiva, sí lo hacen en su contenido. Éstas se caracterizan por flexibilizar la absoluta punición del aborto admitiendo el aborto terapéutico como excepción implícita, la que se presenta, sin embargo, con contornos difusos especialmente para la práctica de los profesionales de salud. Las regulaciones avanzadas van más allá que las desarrolladas haciendo explícitas las justificaciones para el aborto y especificando las condiciones bajo las cuales se puede tomar la decisión de abortar. Tanto en las legislaciones avanzadas como en las desarrolladas, la jurisprudencia de los tribunales viene realizando una labor de precisión en torno a los supuestos permitidos de aborto, con cierta tendencia a ensancharlos ${ }^{5}$. Por último, las

\footnotetext{
${ }^{3}$ Así, en todos los estados mexicanos se considera legal el aborto en casos de violación, y se permite en general (salvo la legislación penal de Guanajuato, Guerrero y Querétaro) cuando hay riesgo para la vida de la mujer. En catorce de los treinta y un estados mexicanos, la permisión se extiende, además, a las deformidades fetales graves y en el estado de Yucatán desde 1922 comprende los factores económicos cuando la mujer ya ha dado a luz a tres o más niños. Para una revisión sinóptica y relativamente actualizada de la regulación del aborto en el derecho comparado y en México, puede verse CARPIZO, Jorge y VALADÉs, Diego, Derechos humanos, aborto y eutanasia, Universidad Nacional Autónoma de México, México, 2008.

${ }^{4}$ Cоoк, R., "Leyes y políticas sobre el aborto: retos y oportunidades", Debate feminista, marzo 1991, pp. 89-129.

${ }^{5}$ Una muestra de ello es la reciente sentencia de la Corte Suprema argentina de 13 de marzo de 2012 recaída en una causa que involucraba la petición de una menor de 15 años -representada por su madreviolada por su padrastro para interrumpir su embarazo y en la que se validó una interpretación extensiva de la regla de excepción que se refería explícitamente a una incapaz mental. Véase Corte Suprema de Argentina, CSJN, "F.A.L/medida autosatisfactiva", 13 de marzo de 2012. Un comentario sobre la misma puede encontrarse en FernÁndez VAlle, Mariano, "El debate legal sobre aborto en la Argentina: avances, reacciones y perspectivas", Género, sexualidades y derechos humanos, Revista Electrónica Semestral del Programa Mujeres, Género y Derechos Humanos. Vol. I, № 1, enero 2013, pp.19-24.
} 
regulaciones despenalizadoras del aborto serían aquellas que sólo criminalizan las intervenciones abortivas desarrolladas por personas que no posean la calificación médica necesaria u otra equivalente y /o la práctica del aborto sin el consentimiento de la mujer embarazada.

Pareciera ser que Chile se ubicaría, dada la rigidez de la punición del aborto, en el grupo de legislaciones básicas. Hay que admitir, sin embargo, que la doctrina penal chilena ha hecho esfuerzos por justificar la atipicidad de la interrupción del embarazo por razones terapéuticas, argumentando que se trataría de una intervención cubierta por la lex artis y reconducible a la causal de justificación establecida en el art. 10 № 10 del Código Penal. Con todo, esta interpretación no es unánime y, aun si lo fuera, difícilmente aporta certeza sobre cuáles intervenciones podrían eventualmente quedar amparadas por esta excepción y cuáles no ${ }^{6}$.

La disonancia de regulaciones en materia de aborto es profundamente incómoda para la teoría y la praxis de los derechos humanos, en cuyo seno se inserta el debate sobre el tratamiento de este fenómeno, ya sea que se exprese en clave de los llamados derechos sexuales y reproductivos, ya sea que se presente como un aspecto asociado a la personalidad del feto. En efecto, la regulación fragmentaria del aborto es difícilmente compatible con la lógica universalizadora de los derechos, porque se disuelve en una casuística estatal que, en general, no resulta restaurada en el nivel internacional.

Vale la pena recordar, a este respecto, que el único tratado internacional que se pronuncia directamente sobre el aborto es el Protocolo sobre los Derechos de la Mujer en África (coloquialmente conocido como Protocolo de Maputo) que complementa la Carta Africana sobre Derechos Humanos y de los Pueblos. En él se establece que los Estados parte deben tomar todas las medidas que resulten necesarias para "proteger los derechos reproductivos de las mujeres a través de la autorización del aborto médico en casos de asalto sexual, violación, incesto, y donde el embarazo pone en peligro la salud mental o física de la madre o la vida de la mujer o del feto". En los demás sistemas, es decir, el sistema universal de Naciones Unidas y en los sistemas regionales europeo y americano, no existe ninguna disposición específica sobre el aborto y son los órganos especializados encargados de vigilar el cumplimiento de los tratados propios de cada sistema, los que a través de recomendaciones, observaciones o en la resolución de casos concretos, se han pronunciado sobre el tema.

En el sistema universal de derechos humanos, existe un solo caso de denuncia o queja individual en el que un órgano supranacional ha responsabilizado a un

${ }^{6}$ Véase al respecto Bascuñán R., A., "La licitud del aborto consentido en Chile", Revista Derecho y Humanidades, № 10, 2004, pp. 143-181. 
Estado por su normativa sobre el aborto. Se trata del Dictamen del Comité de Derechos Humanos en el caso KL v. Perú emitido en el año 2005. En este caso el Estado peruano, a través del Director de un hospital público, le negó el servicio de aborto terapéutico a una menor de 17 años, a la que se había diagnosticado un embarazo de feto anencefálico, o sea, que moriría indefectiblemente durante el embarazo, el parto o al poco tiempo de nacer. En su Dictamen el Comité de Derechos Humanos determinó que el Estado peruano violó el artículo $7^{\circ}$ del Pacto Internacional de Derechos Civiles y Políticos (derecho a no ser sometido a tratos crueles, inhumanos o degradantes), al someter a la adolescente al sufrimiento de tener que continuar la gestación de un embarazo inviable, y el art. 17 del mismo tratado (derecho a no sufrir interferencias arbitrarias en la vida privada), ya que el Estado peruano se negó a actuar conforme a la decisión de abortar de la adolescente. A esto se sumaron sendas violaciones a los arts. 24 (derecho a medidas especiales de protección para los menores) y $2^{\circ}$ (derecho a recurso judicial efectivo) puesto que la menor no contó con un recurso adecuado para impugnar la decisión del Estado de no prestarle el servicio referido ${ }^{7}$.

De manera abstracta, el Comité de Derechos Humanos, a través de su Observación General № 28 artículo 3, La igualdad de derechos entre hombres y mujeres, ha establecido sobre qué aspectos se extiende el deber de informar que tiene cada Estado en relación al cumplimiento de tal derecho. Al respecto, este Comité ha indicado que los Estados deben aportar datos respecto de las tasas de natalidad y el número de casos de muertes de mujeres en relación con el embarazo o el parto y en relación con las medidas que hubiesen adoptado para ayudar a la mujer a prevenir embarazos no deseados y para que no tengan que recurrir a abortos clandestinos que pongan en peligro su vida (párrafo 10). Adicionalmente, deben aportar información que clarifique si el Estado de que se trate da a la mujer que ha quedado embarazada como consecuencia de una violación, acceso al aborto en condiciones de seguridad y acerca de las medidas para impedir el aborto o la esterilización forzados (párrafo 11).

Por su parte, el Comité para la Eliminación de la Discriminación contra la Mujer o Comité de la CEDAW se ha pronunciado, indirectamente, sobre la regulación del aborto en sus Recomendaciones Generales № 21 sobre La igualdad en el matrimonio y en las relaciones familiares y $\mathrm{N}^{\circ} 24$ sobre el artículo 12 de la Convención sobre la eliminación de todas las formas de discriminación contra la mujer - La mujer y la salud. En la Recomendación $N^{0} 21$, a propósito del derecho de las mujeres a no ser discriminadas en el matrimonio y las relaciones familiares y, con énfasis en el derecho a decidir libre y responsablemente el

\footnotetext{
7 Para un comentario de este dictamen puede verse ZúÑIGA, Yanira, "Dictamen del Comité de Derechos Humanos recaído sobre la comunicación n 1153/2003 contra Perú en materia de aborto terapéutico", Revista de Derecho de la Universidad Austral de Chile, Vol. XIX Nº1, julio 2006, pp. 253-267.
} 
número de hijos e intervalo entre sus nacimientos, que contempla la CEDAW; este órgano ha advertido que los informes periódicos de los Estados parte de la Convención "revelan prácticas coercitivas que tienen graves consecuencias para la mujer, como el embarazo, el aborto o la esterilización forzados". En su Recomendación General № 24 sobre Salud y Mujer, al examinar el derecho a no ser discriminada en la esfera de la atención médica, ha expresado que, en lo posible, los Estados deberían "dar prioridad a la prevención del embarazo no deseado mediante la planificación de la familia y la educación sexual y reducir las tasas de mortalidad derivadas de la maternidad mediante servicios de maternidad sin riesgo y asistencia prenatal" y "en la medida de lo posible, debería enmendarse la legislación que castigue el aborto a fin de abolir las medidas punitivas impuestas a mujeres que se hayan sometido a abortos" (párrafo 31, letra c). En opinión del Comité de la CEDAW, "la obligación de respetar los derechos exige que los Estados Partes se abstengan de poner trabas a las medidas adoptadas por la mujer para conseguir sus objetivos en materia de salud (...). El acceso de la mujer a una adecuada atención médica tropieza también con otros obstáculos, como las leyes que penalizan ciertas intervenciones médicas que afectan exclusivamente a la mujer y castigan a las mujeres que se someten a dichas intervenciones" (párrafo 14).

Los dictámenes, recomendaciones y observaciones de estos dos órganos de control son citados, a menudo, como demostrativos de la existencia de un reproche internacional del sistema universal de derechos humanos en relación con la criminalización del aborto, que debiera ser replicado, a su turno, en el nivel interno por el poder legislativo y por los tribunales nacionales. Creo que esta conclusión requiere ser matizada, por varias razones.

Como bien resume Andrew Byrnes, el derecho internacional de los derechos humanos tiene muchas joyas, pero también muchas limitaciones y sería peligroso caer en el error de dar por sentado que se trata necesariamente de un sistema mejor y más adelantado ${ }^{8}$. En relación con los dictámenes, recomendaciones y observaciones de órganos de control en el marco del sistema universal, hay que tener presente que, por mucho que se trate de la interpretación autorizada de los órganos supervisores previstos por cada tratado internacional, cuya relevancia interpretativa es indiscutible de acuerdo a las reglas generales de la Convención de Viena sobre derecho de los tratados; lo cierto es que dichos órganos no ejercen propiamente una función jurisdiccional, a diferencia de lo que ocurre en los sistemas regionales que sí han previsto la existencia de tribunales. En segundo lugar, las funciones de estos

\footnotetext{
${ }^{8}$ Véase, BYRNES, Andrew, "El uso de las normas internacionales de derechos humanos en la interpretación constitucional para el adelanto de los derechos humanos de las mujeres", Facio, Alda y Fries, Lorena. (Eds.) Género y Derecho, LOM Ediciones/La Morada, Santiago de Chile, 1999, pp. 325 -406.
} 
órganos son más o menos amplias en relación con las competencias que les han acordado los propios Estados. Así, el sistema de quejas y denuncias sólo está disponible para los ciudadanos de aquellos Estados que han ratificado las normas convencionales que los instituyen. De manera que para los Estados que no lo han hecho -como ocurre con Chile respecto del protocolo de la CEDAW- la única interpelación posible (y difusa) es a través del mecanismo de observaciones y recomendaciones. Este mecanismo es una competencia básica de los órganos de control, que si bien busca establecer parámetros generales de cumplimiento de los derechos de cada tratado supervisado, su potencial de tutela de los derechos es escaso porque se orienta más a garantizar un régimen de autocontrol estatal que a vertebrar una herramienta de control externo. De ahí que buena parte de la preocupación de los Comités en sus observaciones o recomendaciones se dirija a definir el alcance de la información que deben contener los informes periódicos que están obligados a proporcionar los Estados.

Soy consciente de que se podría contra argumentar que las particularidades del sistema universal en lo concerniente a la garantía de su cumplimiento (descentralización y déficit de coercitividad) no prejuzgan la cuestión de la existencia en él de una norma que proscriba la penalización del aborto. Dicho en términos rawlsianos, no descartan el surgimiento de una suerte de consenso internacional traslapado. Concedo este punto. El problema es que, en mi opinión, no hay demasiados elementos sobre los que apoyar la existencia de semejante norma. No, al menos, con un contenido tan amplio. Por un lado, el surgimiento de obligaciones internacionales sigue siendo prevalentemente voluntarista, por mucho que la práctica de los órganos de control de tratados haya hecho notables esfuerzos para desprenderse de esta especie de pecado original. Las controversias sobre la admisibilidad de reservas en los tratados sobre derechos humanos y los diferentes modelos de recepción y jerarquía de los tratados en el nivel interno, ilustran bien el estado de esta cuestión. Por otra parte, un examen de los pronunciamientos sobre el aborto de estos órganos de control, atento al lenguaje utilizado en los mismos, desestabiliza la tesis de la existencia de una obligación general de despenalizar el aborto, particularmente en lo relativo al aborto a demanda. En efecto, ¿qué otro sentido puede tener la fórmula "en la medida de lo posible", que utiliza el Comité de la CEDAW al recomendar la enmienda de la legislación que castiga el aborto, que no sea el de relativizar esta exigencia y entregarla nuevamente a la voluntad de los Estados?

La situación no es demasiado distinta en el ámbito de los sistemas regionales, no obstante contar con órganos de control con competencias jurisdiccionales. En el ámbito europeo, la Corte Europea de Derechos Humanos (en adelante, la Corte EDH) ha sido especialmente vacilante en su jurisprudencia 
"Una propuesta de análisis y regulación del aborto en Chile desde el pensamiento"

sobre el aborto, en lo concerniente a los derechos procreativos de las mujeres.

En los últimos tres años la Corte EDH ha conocido tres casos en los que ha sido requerida para juzgar la legitimidad de las legislaciones europeas más restrictivas del aborto, esto es, la legislación irlandesa y la polaca. Y en estos tres casos ( $A B C$ v. Irlanda, sentencia de 17 de diciembre 2010, R.R. v. Polonia sentencia de 26.05. 2011, y P. y S. v. Polonia, sentencia de 30.10.2012), ha reiterado una postura profundamente paradójica que, por un lado, hace hincapié en su tradicional doctrina del margen de apreciación -reconociendo a los Estados la libertad de decidir si permiten o no el aborto y con qué alcance- $y$, por otro, manifiesta su voluntad de asegurar una plena efectividad de los derechos de las mujeres. El resultado de este eclecticismo son sendas sentencias condenatorias fundadas exclusivamente en un reproche por incumplimiento de las propias disposiciones internas ${ }^{9}$. Es decir, por inobservancia de las excepciones que los Estados concernidos han establecido respecto de la penalización del aborto (indicación terapéutica, en el caso de Irlanda, y terapéutica y criminológica, en el caso de Polonia). Así las cosas, hasta ahora, la Corte EDH ha omitido pronunciarse abiertamente sobre si tales normas restrictivas vulneran algún derecho general de las mujeres a controlar sus decisiones procreativas. Si bien este derecho no está expresamente consagrado en el Convenio Europeo para la Protección de los Derechos Humanos y de las Libertades Fundamentales, podría derivarse del art. $8^{\circ}$ que contempla el respeto a la vida privada y familiar y que ha sido invocado en todos estos asuntos.

Cabe hacer notar que la utilización de la doctrina del margen de apreciación en estos casos es curiosa considerando que en Europa se concentra el mayor número de legislaciones permisivas del aborto y teniendo en cuenta que la propia Corte EDH se ha pronunciado explícitamente, sobre el otro

\footnotetext{
${ }^{9}$ En el caso contra Irlanda, la condena se funda en la inexistencia de un procedimiento efectivo y accesible que permitiera determinar si una de las demandantes cumplía las condiciones que la propia legislación irlandesa prevé como excepción a la criminalización del aborto (riesgo para la vida de la madre), lo que, en opinión de la Corte, configura un incumplimiento del art. $8^{\circ}$ del Convenio Europeo de Derechos Humanos (derecho al respeto de la vida privada y familiar). En el primer caso citado contra Polonia, la condena se sustentó, primero, en la reticencia de médicos polacos en orden a realizar test genéticos para demostrar la existencia de una grave malformación del feto de la demandante y, luego (una vez practicados estos exámenes y demostrada la mal formación), en la negativa de los facultativos de realizar un aborto a la semana veintitrés, dado que la ley polaca prohíbe que la interrupción del embarazo se realice antes de que el feto sea capaz de sobrevivir fuera del vientre materno. En el último, la Corte estableció que Polonia infringió el art. $8^{\circ}$ ya citado, y, además, los arts. $3^{\circ}$ y $5^{\circ}$ del Convenio (derecho a la libertad y seguridad, y prohibición de tratos inhumanos y degradantes, respectivamente) al haberse obstaculizado a una adolescente embarazada producto de una violación el acceso a la interrupción temprana de su embarazo debido a la inexistencia de un cuadro normativo claro, las tergiversaciones de información provenientes del personal médico y al acoso sufrido por la víctima derivado del incumplimiento del secreto médico, por parte del personal respectivo.
} 
extremo de la cuestión, esto es, el relativo al estatuto jurídico del embrión/ feto. En el caso Vo v. Francia (2004) los tribunales franceses estimaron que la interrupción de un embarazo que debió sufrir una mujer en el sexto mes de gestación como consecuencia de un error médico, no era constitutiva de homicidio culposo dado que el Derecho francés no confiere al feto la calidad de persona. La Corte EDH fue requerida, en consecuencia, para juzgar la compatibilidad de tal interpretación con el Convenio Europeo. En esta oportunidad, la Corte rechazó que el feto fuera una "persona" directamente protegida por el artículo $2^{\circ}$ del Convenio respectivo fundándose en que en la gran mayoría de los Estados miembros del Consejo de Europa el tipo de homicidio involuntario no se aplica a éste. En este sentido, razonó que es posible constatar que los Estados están de acuerdo en que el embrión/feto es parte de la raza humana, pero la potencialidad de este ser y su capacidad de convertirse en persona requiere protección en el nombre de la dignidad humana, sin que esto lo transforme en una "persona" con el "derecho a la vida". De ahí que los eventuales derechos del embrión/feto (susceptibles de conferirse por cada Estado por la vía de protecciones especiales) están implícitamente limitados por los derechos e intereses de la madre.

No parece que ambas líneas jurisprudenciales sean del todo coherentes y, como sea, abren - desde la perspectiva práctica- un enorme terreno a la fragmentariedad y a la incertidumbre. Aunque perturbadoras, estas no son las únicas consecuencias. Desde una perspectiva teórica, la jurisprudencia de la Corte EDH antes referida más que hurgar en las tradiciones morales locales para desentrañar los universales sintetizados en las normas iusfundamentales, ha capitulado ante una noción relativista de los derechos, con evidentes tintes comunitaristas. De mantenerse esta línea jurisprudencial en el futuro la única contribución esperable de la Corte EDH al debate sobre el aborto será describir - de manera más o menos fiel a través del examen de las normas jurídicas de que se trate- cuáles son las tradiciones ético-jurídicas de las sociedades europeas a propósito de la sexualidad, la reproducción y la vida, sin llegar a enjuiciarlas. Creo que la pretensión no sólo es modesta sino impropia de un órgano jurisdiccional. Si bien tiendo a simpatizar con las críticas que desde distintas trincheras, incluida la feminista, se vienen lanzando contra la comprensión moderna de la universalidad (y me serviré de algunas de ellas más adelante), tengo dificultad para concebir una teoría de los derechos humanos y una praxis jurisprudencial que prescindan de una mínima vocación universalizadora. La "neutralidad" judicial respecto de intervenciones estatales que gravitan profundamente sobre los intereses y bienestar de los sujetos no parece ser la postura más apropiada para un tribunal, mucho menos en el caso de un tribunal internacional.

El panorama es ligeramente distinto en el ámbito regional americano. La Corte Interamericana de Derechos Humanos (en adelante, Corte IDH), en su 
reciente sentencia de 28 de diciembre de 2012, recaída en el asunto Artavia Murillo y otros (Fertilización in vitro) vs Costa Rica, acaba de despejar las dudas sobre la correcta interpretación del art. 4.1 de la Convención Americana, en lo relativo al estatuto jurídico del embrión. Así, ha establecido -ratificando, de paso, la opinión de la Comisión Interamericana en el asunto "Baby Boy" (Informe 23/81)- que, de acuerdo a la interpretación histórica y sistemática de los antecedentes existentes en el sistema interamericano, no es procedente otorgar el estatus de persona al embrión. Recordemos, a estos efectos, que el mencionado art. 4.1 establece que "toda persona tiene derecho a que se respete su vida" y que "este derecho estará protegido por la ley y, en general, a partir del momento de la concepción". Agrega, además, que "nadie puede ser privado de la vida arbitrariamente".

Al respecto, la Corte IDH ha señalado que la voz "concepción" utilizada en esa disposición, si bien es objeto de debate biológico, ético y religioso, no puede ser comprendida como un momento o proceso ajeno al cuerpo de la mujer, dado que un embrión no tiene ninguna posibilidad de supervivencia si la implantación no se produce. De ahí que el tribunal haya interpretado dicha expresión como una referencia al momento en que ocurre la implantación, razón por la cual, antes de este evento no procedería aplicar la disposición en cuestión. Por otra parte, la fórmula "en general" que también ocupa esa norma, permite -en opinión de la Corte- inferir excepciones a la protección que la propia disposición dispensa y que se traducen en la posibilidad de establecer un sistema gradual e incremental de tutela de la vida, en atención a su desarrollo. En consecuencia, la decisión de la Sala Constitucional de Costa Rica, que condicionó la posibilidad de realizar la técnica de fertilización in vitro a que no hubiera pérdida embrionaria (condición que es imposible desde el punto de vista práctico), implicó para los demandantes, habida cuenta de su severidad, una restricción desproporcionada que produjo, a su turno, la vulneración de varios de sus derechos. A saber, el derecho a la integridad personal, la libertad personal, la vida privada, la intimidad, la autonomía reproductiva, el acceso a servicios de salud reproductiva, a fundar una familia y el derecho a la igualdad.

A pesar de que el fallo antes reseñado no se refiere directamente al aborto, es evidente que elabora varios aspectos que son relevantes para este debate. La doble tesis de la Corte IDH -es decir, el reconocimiento de los derechos sexuales y reproductivos y la negación de la calidad de persona al embriónabre, sin duda, la puerta al enjuiciamiento de las leyes restrictivas del aborto en la región. Lo anterior, porque, a diferencia de la Corte Europea, la Corte IDH no sólo no ha replicado la doctrina del margen de apreciación en su jurisprudencia sino que acaba de descartarla explícitamente en el caso Atala vs. Chile, respecto de una materia -la prohibición de discriminación por la 
razón de orientación sexual - en la que su homóloga europea viene utilizando este criterio también con cierta recurrencia ${ }^{10}$.

En parte, lo anterior explica que el fallo en el caso Artavia v. Costa Rica haya concitado tanta atención en un medio jurídico como el chileno, usualmente poco interesado en la jurisprudencia interamericana, dando origen a una verdadera explosión de críticas mediáticas entre quienes cultivan posiciones conservadoras ${ }^{11}$. La pieza faltante de este puzzle, es la puesta en jaque a la sentencia del Tribunal Constitucional chileno sobre la píldora del día después. Como es sabido, el Tribunal Constitucional chileno declaró inconstitucional en 2008 una política pública de suministro de este medicamento, sobre la base de una tesis que admitió como premisa la personalidad del embrión/feto. Para construir esta polémica tesis se sirvió, de manera prevalente, de lo dispuesto

${ }^{10}$ El tratamiento de la prohibición de discriminación por razón de orientación sexual no ha sido lineal en la jurisprudencia de la Corte EDH. Si bien en el asunto Salgueiro da Silva Mouta vs. Portugal (1996) la Corte $\mathrm{EDH}$ consideró que la decisión de un tribunal nacional de retirar a un padre homosexual la custodia de su hija menor de edad, con el argumento que la niña debería vivir en una familia portuguesa tradicional, carecía de relación razonable de proporcionalidad entre la medida tomada (retiro de la custodia) y el fin perseguido (protección del interés superior de la menor de edad), lo cierto es que respecto del acceso al matrimonio en el caso de las parejas homosexuales, la Corte se ha mantenido fiel a su doctrina del margen de apreciación, mientras que ha reconocido este derecho a las personas transexuales (Caso Goodwin v. Inglaterra, 1997). En su sentencia de junio de 2010 (caso Schalk v. Kopf contra Austria) la Corte Europea volvió a aplicar la doctrina del margen de apreciación para descartar la alegación de infracción a la prohibición de discriminación contenida en el Convenio Europeo para la Protección de los Derechos Humanos y Libertades Fundamentales (art.14) derivada de la exclusión de las parejas homosexuales del régimen del matrimonio, considerando entre otras cosas la proliferación de regímenes de reconocimiento de uniones civiles. De manera que el sistema europeo se ha venido vertebrando en esta materia sobre la base del reconocimiento a los Estados de una esfera de interpretación y aplicación más o menos flexible. Alcanza en mayor o menor medida a la vida privada y no necesariamente al derecho a fundar familia y deja fuera el derecho igual al matrimonio legitimando las regulaciones diferenciadas de parejas de hecho. Es precisamente en este punto donde la Corte Interamericana se aparta de su homóloga europea. En el caso Atala v. Chile (sentencia de 24 de febrero de 2012) la Corte IDH rechazó el intento del Estado chileno en orden a introducir el estándar del margen de apreciación bajo el alegato de que "el Sistema [Interamericano de Derechos Humanos] requiere de la credibilidad y confianza de los Estados miembros [... que] puede ser afectada si la Corte toma un rol demasiado regulador, sin otorgar consideración al sentir mayoritario de los Estados" y aludiendo a que "la orientación sexual no era una categoría sospechosa de la cual hubiera un consenso durante el año 2004 (fecha en la que se dicta la sentencia de la Corte Suprema chilena que privó a Karen Atala de la tuición de sus hijas). Al respecto la Corte fue enfática al sostener que "si bien es cierto que ciertas sociedades pueden ser intolerantes a condiciones como la raza, el sexo, la nacionalidad o la orientación sexual de una persona los Estados no pueden utilizar esto como justificación para perpetuar tratos discriminatorios. Los Estados están internacionalmente obligados a adoptar las medidas que fueren necesarias 'para hacer efectivos' los derechos establecidos en la Convención, como se estipula en el artículo $2^{\circ}$ de dicho instrumento interamericano, por lo que deben enfrentar las manifestaciones intolerantes y discriminatorias, con el fin de evitar la exclusión o negación de una determinada condición". No contenta con ello la Corte IDH calificó el principio de igualdad como norma de ius cogens.

11 Un listado bastante completo de las cartas y columnas publicadas en diarios de circulación nacional chilena puede encontrarse en http://www.eticayreproduccionhumana.udp.cl/fallo.html. 
en el art. 4.1 de la Convención Americana. Evidentemente, esta jurisprudencia constitucional se queda, ahora, coja.

Resta ver si la promesa de universalización regional de los derechos sexuales y reproductivos envuelta en esta última jurisprudencia interamericana se concreta a corto plazo.

\subsection{La brecha entre normatividad y eficacia}

La eficacia del crisol de regulaciones estatales sobre el aborto es también variada. Pese a las dificultades para contar con estadísticas exactas, se sabe que en contextos normativos restrictivos los abortos continúan practicándose de manera habitual y en condiciones de alto riesgo para las mujeres. Según cifras de la Organización Mundial de la Salud, se estima que de los embarazos no planeados (80 millones de los 210 millones anuales), 46 millones (58\%) terminan interrumpiéndose. De esa cifra, alrededor de 19 millones se producirían en países donde la intervención voluntaria del embarazo es ilegal. La región con la tasa más alta de abortos sería Europa Oriental, con 43 abortos por cada 1.000 mujeres en 2008; mientras que la región con la tasa más baja sería Europa Occidental, con 12. En América Latina se estima que la tasa de aborto para el año 2008 fue de 4.4 millones y de ellos prácticamente el 95\% correspondieron a abortos inseguros ${ }^{12}$, siendo el riesgo de muerte de 370 por cada 100.000 casos $^{13}$.

Esos datos sugieren que, contrariamente a lo previsible, donde se concentran las restricciones legales más severas -América Latina, por ejemplo- las cifras de aborto son más abultadas; mientras que la tasa de abortos desciende, de manera significativa, en aquellos países donde la legislación es más permisiva e involucra, además, la cobertura sanitaria pública para la interrupción del embarazo. Un caso paradigmático es el de Holanda, donde el aborto se puede practicar desde la concepción hasta la viabilidad del feto (aproximadamente, hasta las 24 semanas) y que, sin embargo, exhibe la tasa de abortos más baja de la Unión Europea, debido a un exitoso plan nacional de educación sexual.

La clandestinidad del aborto acarrea varios problemas, algunos de los cuales han sido puestos de relieve por el Comité de Derechos Humanos y por el Comité de la CEDAW, como vimos en la sección anterior. Sin agotar la lista, los abortos clandestinos generan un grave problema de salud pública, debido

12 Un aborto inseguro es un procedimiento para terminar un embarazo no deseado llevado a cabo por personas carentes de las habilidades necesarias o en un ambiente que no conforma los estándares médicos mínimos, o ambos.

${ }^{13}$ Cifras elaboradas por Womens Link Worldwide a partir de estadísticas de la OMS. Véase WoMENS LINK WORLDWIDE, El aborto en cifras. En: http://www.womenslinkworldwide.org/pdf_programs/ es_prog_rr_col_factsheets_cifras.pdf 
a la frecuencia de complicaciones físicas y el consiguiente incremento de las cifras de mortalidad materna; daños a la salud psicológica de las mujeres y colisiones entre los deberes de denuncia y el secreto médico que afectan al personal de salud. A ello se suman problemas de desigualdad social, económica, étnica y de género, dado que son las mujeres más vulnerables las más expuestas a la práctica de abortos inseguros. Por otra parte, si bien las cifras de enjuiciamientos penales por aborto son relativamente bajas en la región, son también las mujeres pertenecientes a grupos sociales desventajados las principales destinatarias de estos procesos y en condiciones que, con cierta frecuencia, implican violación de garantías judiciales ${ }^{14}$. Todo ello configura un listado no despreciable de afectaciones a varios derechos: entre otros, la vida y salud de las mujeres, la igualdad, la libertad reproductiva y la intimidad.

Lo anterior plantea dudas sobre la idoneidad de la utilización de la herramienta penal como política de protección del no nato, que repercuten necesariamente sobre la cuestión -por sí sola espinosa- de la justificación de la intervención estatal en esta materia. Sin adentrarse de momento en este terreno, resulta obvio que el déficit de eficacia de las normas punitivas del aborto es susceptible de encuadrarse en el problema más amplio relativo a las funciones de la pena en lo concerniente a la prevención del delito. Sin embargo, presenta también ciertas especificidades. En particular, la brecha entre normatividad y eficacia es sintomática de un fenómeno de contradicción entre pautas morales declaradas a nivel normativo y prácticas y vivencias sociales.

La realidad del aborto dibuja una gran mancha en el cuadro de los avances que se han obrado en las últimas décadas en materia de reconocimiento y derechos de las mujeres, los que, a menudo, son revelados como la demostración categórica de la inescindible relación entre democracia y bienestar. Visto lo anterior, cabe plantearnos, entonces, la siguiente pregunta: ¿qué motiva que se sancionen o mantengan leyes punitivas del aborto que muy pocas sociedades parecen estar dispuestas a aplicar, al punto que se escamotea deliberadamente su eficacia sancionatoria y, en el mejor de los casos (o habría que decir, en el peor), esta se dirige de manera preferente a las mujeres más vulnerables?

Las explicaciones a esta paradoja son variadas y yuxtapuestas. Así, por ejemplo, en un estudio histórico-comparado sobre Brasil, Argentina y Chile, Mala Htun analizó las reformas liberalizadoras de la familia obradas en las últimas tres décadas del siglo pasado y evaluó el impacto que en ellas tuvieron los siguientes

\footnotetext{
${ }_{14}$ Para una caracterización de esta situación en el caso chileno, puede consultarse CASAS, Lidia, Mujeres procesadas por aborto, Foro Abierto de Salud y Derechos Reproductivos, Santiago, 1996, y SeRVENTYGleEsOn, Molly, "Mujeres en las sombras. Un estudio sobre aborto en Chile", Independent Study Project (ISP) Collection Yale University. Paper 860, 2010. En: http://digitalcollections.sit.edu/cgi/viewcontent. cgi?article $=1862 \&$ context=isp_collection.
} 
factores: a) la transición de dictadura a la democracia, b) las relaciones entre la Iglesia y el Estado, c) los esfuerzos de reformistas liberales y feministas, y d) la influencia de las normas internacionales. Htun concluye que los procesos de modernización económica y estatal, impulsados por los gobiernos dictatoriales en las últimas décadas del siglo XX en América Latina, permitieron la reforma de la familia en clave de equidad de género, debido a que la subordinación de la mujer en la familia era vista como un resabio que impedía el desarrollo social y económico. Lo anterior, unido a que los gobiernos militares de estos tres países se valieron de la asesoría de especialistas para elaborar esta nueva regulación, abrió la puerta a las tendencias normativas internacionales y las demandas de equidad de género que los movimientos feministas venían popularizando desde la década de los $70^{15}$. Este caldo de cultivo repercutió directamente en algunas reformas de equidad de género dentro de la familia matrimonial (por ejemplo, el establecimiento de la capacidad de la mujer casada o el reconocimiento de derechos patrimoniales dentro del matrimonio) y facilitó la regulación del divorcio vincular, pese a la oposición de la Iglesia. Pero no logró vencer, en cambio, las resistencias conservadoras en lo concerniente a la regulación de los derechos sexuales y reproductivos -en particular, respecto de la despenalización del aborto- que han logrado bloquear estas reformas en el marco de los gobiernos democráticos. ¿Qué genera que el aborto se haya transformado en Latinoamérica en un verdadero nudo gordiano? Según Htun, a diferencia de lo que ha ocurrido con el resto de las reformas en materia de familia, el aborto genera una polarización y una defensa moral en clave absolutista que deja muy poco espacio al compromiso político y a la formación de coaliciones en favor de su despenalización. De ahí que la regulación del aborto en América Latina -salvo en el caso de Cuba y más recientemente de México DF y Uruguayhaya cambiado muy poco desde la promulgación de los códigos penales en la segunda mitad del siglo XIX y primera mitad del siglo XX, y sea relativamente impermeable a los procesos de democratización que ha vivido la región y a los procesos globales de adelanto de la mujer.

Sin embargo -como hemos apuntado- las normas punitivas del aborto son tan incombustibles como escasamente aplicadas. Todo esto sugiere que por muy vociferante que sea el discurso de protección de la vida de embriones o fetos en el ámbito latinoamericano, este discurso resulta desdibujado por una extendida práctica social de tolerancia hacia el aborto que prefiere relegar su práctica al terreno de lo oculto, antes que defender con coherencia los postulados morales plasmados en las normas jurídicas que prohíben la interrupción

15 Htun, Mala, Sexo y Estado. Aborto, divorcio y familia bajo dictaduras y democracias en América Latina, Ediciones Universidad Diego Portales, Santiago (Chile), 2010. 
del embarazo. Podría contentarme con calificar esta anomalía -como lo hacen varios informes sobre el aborto- de hipocresía social, pero me parece más útil para el análisis que desarrollaré en lo sucesivo, proponer una hipótesis que explique este comportamiento.

\subsection{El cautiverio de la maternidad ${ }^{16}$. Un ensayo de explicación del déficit de aplicación de las normas punitivas del aborto}

Hay poderosas razones para sostener que el déficit de aplicación de las normas que criminalizan el aborto se vincula, en gran medida, con la complejidad de la maternidad en tanto fenómeno social. La maternidad está lejos de ser sólo una vivencia individual y es, en cambio, un continente de simbolizaciones/representaciones sociales, prácticas y relaciones en torno al cuerpo de las mujeres, la reproducción y la dependencia o el cuidado. Cada mujer se inserta en este delicado entramado como un engranaje más y su libertad para "apropiarse" de la experiencia de la maternidad, como un proyecto de vida individual, está profundamente condicionada por diversos factores. Entre otros, la riqueza económica de la que dispone, la posición social que ocupa, los grupos sociales y étnicos de los que forma parte, y sus relaciones de parentesco y conyugalidad. El Estado, por su parte, actúa como eje de rotación de este conjunto de relaciones y, comúnmente, como vector de las representaciones sociales sobre las que aquel reposa.

Vista así la cuestión, en muchos sentidos -y no sólo respecto de las restricciones legales al aborto- la mayoría de las mujeres vive cautiva de la maternidad. En la actualidad este cautiverio se vertebra sobre una estrategia que se apoya más en las representaciones sociales que en la mera represión para lograr su objetivo: mantener convencidas y satisfechas a las mujeres para que, a pesar de las enormes dificultades que la maternidad implica, sigan desarrollando gustosas la función social de reproducción y cuidado, sin comprometer su creciente inserción en el mercado laboral y sin poner en jaque el discurso de los derechos. ¿Cómo se logra lo anterior? La estrategia consiste en reforzar la simbolización de la maternidad como única forma correcta de autorrealización individual de la feminidad. En este esquema es preferible, entonces, tolerar cierta desviación. Más que encarcelar a la mujer que se aparta de esta normatividad socio-cultural, lo crucial es simbolizarla como "fallida" (perversa, delincuente, enferma, etc.), al mismo tiempo que se glorifica a aquella otra que vive feliz su cautiverio.

16 He tomado la metáfora del cautiverio del extenso trabajo de Marcela Lagarde que busca decodificar el fenómeno de la opresión femenina a través de la observación y análisis de una serie de tipologías antropológicas. LAGARDE, Marcela, Los cautiverios de las mujeres. Madresposas, monjas, putas, presas y locas, Horas y Horas la Editorial, Madrid, 2011. 
Entiendo por representación social un conjunto coherente y compartido de significaciones sobre ciertos hechos (algunos de carácter biológico, como la capacidad reproductora de las mujeres) que se nutre de experiencias, de modelos de pensamiento, de informaciones y de tradiciones culturales. Todo ello da origen a un repertorio de simbolizaciones que reelabora constantemente las relaciones entre los sujetos y la sociedad y que contribuye, de manera potente, a la definición de identidades personales. Por lo mismo, la representación social de la maternidad -como cualquier otra- no es estática. Sin embargo, históricamente se ha caracterizado por perfilarse en tensión entre el poder que la capacidad de gestar y de reproducir la especie humana le otorga a las mujeres y la necesidad social de "domesticar" dicho poder para servir a fines colectivos. Podríamos decir, entonces, que la representación social de la maternidad ha estado signada por una pulsión hacia la instrumentalización de los cuerpos de las mujeres.

No parece que dicha tensión se haya superado en la actualidad, aun reconociendo que ha sufrido importantes erosiones. Por el contrario, ciertas investigaciones indican que se reelabora en permanencia ${ }^{17}$. En este sentido, Elizabeth Badinter destaca el surgimiento -como una suerte de antídoto a los movimientos de liberación sexual y reproductiva de décadas pasadas- de un nuevo registro de representación de la maternidad, de matrices teóricas variopintas (la ecología, las ciencias del comportamiento que se apoyan en la etología y un feminismo de signo esencialista) e influjo globalizador. Éste tiene como núcleo ideológico una propuesta de "retorno a la verdadera naturaleza femenina", anclada en la maternidad, la que, a su vez, se presenta como la auténtica llave para lograr el bienestar de la humanidad. La sacralización del parto natural, la teoría del apego, la glorificación de la leche materna y el rescate "científico" del instinto maternal, son nuevas manifestaciones de una ideología de la maternidad reciclada ${ }^{18}$.

Este reciclaje aspira a satisfacer funciones más complejas que las de antaño. Tiene por finalidad asegurar que otros proyectos de vida que compiten con la maternidad-como, por ejemplo, la vida laboral-no logren eclipsarla, ni sean vivenciados como contradictorios por las mujeres.

Y todo esto ¿para qué? Ni más ni menos que para mantener el statu quo. Resulta que, contrariamente a lo que confiesa el discurso conservador, en esto no sólo está comprometida la protección de familia, sino todo el sistema de producción y reproducción del Estado, tal y como lo conocemos. Traducido

\footnotetext{
17 Un interesante y documentado análisis de esta cuestión, aplicado al caso argentino entre los años 1890 y 1940, puede encontrarse en NARI, Marcela, Políticas de maternidad y maternalismo político, Editorial Biblos, Buenos Aires, 2004.

${ }^{18}$ Véase BADINTER, Elizabeth, La mujer y la madre. Un libro polémico sobre la maternidad como nueva forma de esclavitud (traducción de Montse Roca), La esfera de los libros, Madrid, 2011.
} 
en jerga macroeconómica, está en juego la inyección de mano de obra suficiente para garantizar crecimiento económico, la mantención del sistema de las pensiones y, en general, la preservación de una estructura de gestión de la dependencia y el cuidado que, hasta ahora, descansa mayoritariamente sobre el trabajo gratuito femenino. Alterar este complejo de relaciones significaría reconfigurar profundamente la distribución de derechos y responsabilidades en nuestras sociedades.

¿Qué rol cumple en este esquema la criminalización del aborto? Creo que la respuesta, a estas alturas, debiera ser previsible. La persistencia del tipo penal refuerza la representación de la maternidad como ideal socio-normativo, más por su potencial performativo que por la amenaza de sanción. En otros términos, la punición efectiva de los abortos no es estrictamente necesaria para imponer la ideología de la maternidad -después de todo, el sentimiento de culpa de las mujeres parece servir mejor a este propósito- y, en contrapartida, una aplicación estricta de la norma penal sí podría amenazar este objetivo, alimentando un malestar susceptible de catalizar una subversión. Si no fuera así los entusiastas discursos que alaban a aquellas mujeres que "deciden" no interrumpir sus embarazos, transformando en virtud el cumplimiento de las normas que criminalizan el aborto $^{19}$, serían sencillamente absurdos.

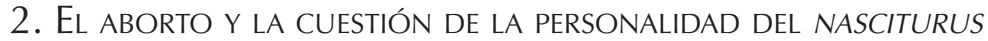

\subsection{El debate entre conservadores y liberales}

Los debates sobre el aborto se plantean tradicionalmente como vías indirectas para despejar la resbaladiza cuestión de qué entendemos por una persona. Esta deriva tiene poco o nada de sorprendente. Como nos recuerda Tamayo y Salmorán, en la modernidad las personas devienen los personajes de una obra teatral cuyo contenido discursivo son los derechos ${ }^{20}$. La persona es, entonces, el sujeto paradigmático de derechos. De ahí que resulte tan estratégico para las tesis conservadoras, atribuirle al pre embrión/embrión/ feto este carácter.

\footnotetext{
${ }^{19}$ Así, por ejemplo, la prensa chilena informaba recientemente del embarazo de Katherine Orellana, una ex participante de un concurso de talentos, exaltando su decisión de no abortar pese a su soltería. El Diario la Nación presentaba la noticia de la siguiente manera: 'No me importa que la gente me apunte con el dedo', dijo clara y con total orgullo la cantante Katherine Orellana sobre su embarazo en el matinal de Canal 13 'Bienvenidos'. La ex integrante de voz rasposa del programa 'Rojo' contó detalles de su dulce espera como madre soltera, el cual, según confesó, decidió llevar a término a pesar de que su ex pareja le pidió que abortaran, tras lo cual optó por cortar todo tipo de lazos con el hombre" (los destacados son míos). Extracto de La Nación, Edición digital, 04/12/2012.
}

20 Tamayo y Salmorán, Rolando, "El sujeto de derecho", Isonomía: Revista de Teoría y Filosofía del Derecho, núm. 3, octubre 1995, pp. 167-189. 
La afirmación de la personalidad del no nato, que constituye el núcleo discursivo de las tesis conservadoras, se apoya sobre una doble analogía. Por un lado, estima al nasciturus semejante a un individuo nacido y, por tanto, titular de derechos e intereses. Y, por otro, postula que la interrupción intencional de un embarazo debiera ser tratada, en consecuencia, de manera similar a un homicidio, es decir, penalizarse. Para esta aproximación, las evidentes diferencias biológicas entre un no nato y un nacido no son un dato suficiente para descartar la humanidad del embrión/feto y devienen, en cambio, irrelevantes. En efecto, los detractores del aborto arguyen que la esencia de lo humano se plasma en la concepción, momento en el que se transmitiría el código genétiCo, y que cualquier otra diferencia física o de habilidades entre el no nato y el individuo nacido, es meramente accidental. Dicho en otros términos, una vez establecido que la vida se origina antes del nacimiento la caracterización fáctica de las distintas etapas de la gestación se vuelve superflua. De esta manera, en las tesis conservadoras, la potencia y el acto no sólo están vinculados sino que terminan confundiéndose.

Como se sabe, esta es la forma más habitual de argumentar en la doctrina chilena ${ }^{21}$. Llevada esta línea de análisis a sus últimas consecuencias anula prácticamente toda justificación del aborto. Sólo deja a salvo lo que en la teología moral católica se conoce como doctrina del doble efecto. Sin embargo, resulta igualmente evidente que no todos los conservadores son tan categóricos en su defensa de la prohibición del aborto. Probablemente el ejemplo más claro de que existe un cierto crisol de propuestas dentro de las posiciones conservadores esté dado por la organización Católicas por el derecho a decidir, fundada en EE.UU. en la década de los 70. Desde luego, existen también católicos que sin ser "prochoice", admiten el aborto terapéutico más allá de la doctrina del doble efecto y aceptan, incluso, otras hipótesis como el aborto en caso de violación y cuando existe feto inviable.

Merece la pena, con todo, analizar con más detalle aquí la doctrina del doble efecto, dado que, como veremos más adelante, es esta la única excepción normativa que reconoce el derecho chileno a la prohibición general del aborto, después que la ley № 18.826 de 1989 modificara el art. 119 del Código Sanitario en lo relativo al aborto terapéutico.

Quien ha realizado el ejercicio más profundo de justificación moral de esta doctrina es John Finnis ${ }^{22}$. Este autor la resume de la siguiente manera: "si la madre

\footnotetext{
${ }^{21}$ Para una síntesis de la doctrina chilena en esta materia, puede verse FIGUerOA, Rodolfo, "Concepto de persona, titularidad del derecho a la vida y aborto", Revista de Derecho de la Universidad Austral de Chile, Vol, XX, № 2, diciembre 2007, pp. 95-130.

22 Finnis, John, "Pros y contras del aborto", VVAA, Debate sobre el aborto. Cinco ensayos de filosofía moral, Ediciones Cátedra, Madrid, 1992, pp. 108-142.
} 
necesita tratamiento médico para salvar su vida, lo obtiene, aunque se sepa que el tratamiento matará al niño no nacido, ya que, después de todo, su cuerpo es su cuerpo [...] ¿Cuál es la condición? Que el tratamiento médico no consista en un ataque directo o intervención directos contra el cuerpo del niño ya que, después de todo, el cuerpo del niño es el cuerpo del niño, no de la mujer"23.

Como advierte García Pascual, la doctrina del doble efecto es eminentemente problemática. Entre otras cosas, por su dificultad para condensar coherentemente la variada casuística médica en materia de aborto terapéutico. Esta casuística es bastante menos estricta de lo que plantea esta doctrina y tiende, en cambio, a presentar la muerte del feto siempre como una consecuencia indeseada, diluyendo las fronteras entre una interrupción del embarazo producida como medio para salvar la vida de la madre o como fin directamente ${ }^{24}$.

Por otra parte, si bien la doctrina del doble efecto busca proveer a la mujer embarazada de una justificación moral para salvar su propia vida, utilizando la interrupción del embarazo como medio para tal fin, dicha justificación no alcanza, necesariamente, al tercero. En efecto, si consideramos que la mujer y el feto son igualmente personas, resulta forzoso concluir que será difícil para un tercero discernir a quién se debe salvar y a quién se debe dejar morir, sobre todo, si el feto ocupa normalmente, en este esquema, la situación de víctima o parte más débil. Este dilema se transforma en una verdadera piedra en el zapato si advertimos -como lo ha hecho notar Judith Jarvis Thomson- que al analizar moralmente el aborto, no es posible obviar, desde el punto de vista práctico, la situación del tercero, porque no contar con la ayuda ajena pone a la mujer en la posición de tener que interrumpir su embarazo en condiciones extremadamente riesgosas para su propia salud.

Thomson, en el marco de su polémica con Finnis, propone un ejemplo que busca poner de relieve la fragilidad e imprecisión de un criterio fundado en la inocencia de un sujeto, como guía u orientación de la moralidad de las decisiones sobre la vida o muerte que pueden adoptar otros ${ }^{25}$. Su ejemplo consiste en un lanza misiles que sólo puede ser activado por niños y, a través del cual, una nación beligerante amenaza con atacar a otra. La destrucción del misil por parte de la nación amenazada implicaría la muerte de los niños que son utilizados para activarlo. Hasta aquí, el ejemplo de Thomson se encuadra fácilmente en la doctrina del doble efecto. Para complejizar la cuestión, entonces, la autora

${ }^{23}$ FinNIS, John, "Pros y contras", cit. nota n. 22, p. 136. Los destacados son del texto citado.

${ }^{24}$ García Pascual, Cristina, "Cuestiones de vida y muerte. Los dilemas éticos del aborto", Derechos y Libertades, Número 16, Época II, enero de 2007, pp. 181-209.

${ }^{25}$ Thomson, Judith, "Derechos y muertes", VVAA. Debate sobre el aborto. Cinco ensayos de filosofía moral Ediciones Cátedra, Madrid, 1992, pp. 143-159. El ejemplo comentado en el texto se desarrolla en las páginas 152 y 153. 
introduce dos variantes posibles y alternativas al referido ejemplo, relacionadas con el tiempo de reposición del lanza misiles en caso de ser destruido y el tiempo de entrenamiento de los niños que lo activarían, en caso de muerte de estos. En la primera alternativa (A), el tiempo de reposición del lanza misiles sería de dos años y, en cambio, el tiempo de entrenamiento de los niños sería de un día. En la segunda (B), los tiempos se invierten para cada factor: el entrenamiento de los niños duraría dos años y la reposición del lanza misiles se lograría en un día. Veamos el resultado de estas combinaciones: En la alternativa (A) si se destruye el lanza misiles sólo se quitaría indirectamente la vida a los niños porque para conseguir el objetivo (la autodefensa) no se requiere en estricto rigor matarlos, es decir, no es un fin en sí mismo. Tanto es así que si los niños sobrevivieran milagrosamente, el objetivo se conseguiría de todas formas. En la alternativa (B), en cambio, la muerte de los niños sí es necesaria para lograr el objetivo propuesto, tanto que si, por milagro nuevamente, estos sobrevivieran, el Estado amenazado se vería compelido a intentarlo de nuevo para asegurar su supervivencia. Una aplicación coherente de la doctrina del doble efecto debiera hacernos concluir que en la alternativa (A) el Estado amenazado está moralmente habilitado para atacar al eventual agresor, mientras que en el caso (B) en cambio, no lo está. ¿Verdaderamente es esto lo que cualquiera de nosotros concluiría? La respuesta parece ser negativa. El ejemplo de J.J. Thomson ilustra, en consecuencia, que la inocencia o falta de culpa de un sujeto es irrelevante en este caso. Y siendo así, debiera serlo también respecto del aborto. Probablemente esta es la razón por la que, intuitivamente, la mayoría de los conservadores tiende a no alinearse con una posición tan extrema.

Claro está, no obstante, que la idea de que el nasciturus es persona, aglutina por sí sola las propuestas antiabortistas de signo conservador, aun admitiendo cierta pérdida de coherencia en su aplicación práctica.

Tal idea ha sido ampliamente controvertida por el pensamiento liberal. Podría decirse que para la postura liberal cuestionar esta tesis es tan estratégico como para la posición conservadora afirmarla. No porque los liberales desprecien la vida o cuestionen la premisa de que ésta se inicia antes del nacimiento. Sino, más bien, porque -como es de sobre conocido- el pensamiento liberal se vertebra sobre el postulado de separación entre la moral y el derecho. Como explica Ferrajoli, a partir de la vitalidad del embrión (premisa empíricamente verdadera) no se puede deducir -sin incurrir en falacia naturalista- que el no nato es una persona desde el punto de vista jurídico, porque esta última aserción es de carácter prescriptivo (implica ser sujeto de derechos) ${ }^{26}$. En consecuencia,

${ }^{26}$ Ferrajol, Luigi, "La cuestión del embrión: entre el derecho y la moral", Revista de la Facultad de Derecho de México, № 245, 2006 , pp. 255-275. 
la afirmación de que el nasciturus es persona es, en realidad, una concepción moral que, como tal, es compartida por un buen número de individuos y rechazada por otros tantos. Adicionalmente, desde el punto de vista liberal, la reprobación moral de un determinado comportamiento -como, por ejemplo, la destrucción del embrión/feto- no es por sí sola una razón suficiente para justificar la prohibición jurídica del aborto. Sólo la lesividad puede justificar la punición de una conducta.

La posición de Ronald Dworkin es ilustrativa de esta forma de razonar ${ }^{27}$. Dworkin rechaza la tesis de la personalidad moral del no nato porque ésta presupone la afirmación de que se trata de criaturas con intereses propios. A juicio de este autor, sólo las capacidades más complejas de un individuo pueden correlacionarse con la noción de intereses, y éstas son adquiridas por el feto prácticamente al final del embarazo (alrededor de la semana 30). Admite, en cambio, que la vida tiene un valor intrínseco y abortar implica atentar contra ese valor. Y, aun así, concluye que un Estado no puede criminalizar el aborto en general, ni siquiera en la hipótesis contrafáctica de que la mayoría de los ciudadanos piense que abortar (excepto quizás cuando la vida de la madre está en juego), sea un insulto intolerable a los valores inherentes a la vida humana.

¿Por qué esto no sería legítimo a pesar de ser teóricamente democrático (en el sentido de ley de las mayorías)? Porque el efecto de coacción sobre unas personas determinadas - las mujeres embarazadas- sería mucho mayor que el valor a proteger pudiendo Ilegar a destruir la vida de aquellas. Y porque un Estado no puede coartar la libertad para proteger un valor cualquiera (incluso el valor intrínseco de la vida) cuando el efecto sobre un grupo de ciudadanos resulte especialmente grave. Desde luego, mucho menos puede hacerlo cuando la comunidad se halle seriamente dividida acerca de qué tipo de respeto requiere ese valor y cuando las opiniones de la gente acerca de la naturaleza de ese valor reflejen convicciones esencialmente religiosas que son fundamentales para la personalidad moral, como es el caso en la gran mayoría de las sociedades ${ }^{28}$.

Un número importante de las críticas liberales contra las posiciones antiabortistas buscan poner de relieve que la personalidad moral del embrión/feto -como lo sugiere Dworkin- es también discutible. Estas críticas pueden agruparse en dos registros que tienden a entremezclarse: a) la falta de viabilidad del embrión/ feto, es decir, su incapacidad de vivir fuera del útero materno y b) su falta de autonomía moral, en un sentido moderno. Esta última crítica -que se presenta

27 Dworkin, Ronald, El dominio de la vida: una discusión sobre el aborto, la eutanasia y la liberal individual, Editorial Ariel, Barcelona, 1993.

${ }^{28}$ Dworkin, Ronald, El dominio, cit. nota n. 27, pp. 203- 206. 
como la objeción más contundente dado los avances tecnológicos obrados en lo concerniente a la viabilidad y la posibilidad fáctica de la maternidad subrogada-sostiene que la noción de persona no es susceptible de construirse sobre la sola idea de trasmisión del código genético humano, como lo hacen las tesis conservadoras. Lo anterior debido a que la autonomía moral es una categoría que ha sido perfilada convencionalmente por el pensamiento jurídico moderno, de manera más exigente. A través de la repetida metáfora que distingue entre una bellota y un roble, los liberales contradicen la confusión de la potencia y el acto en las que se fundan las tesis conservadoras, y sostienen, en cambio, que el nascituris carece de ciertas características que serían constitutivas de la autonomía en un sentido moral.

¿Cuáles serían los rasgos distintivos de esta autonomía moral y en qué momento se adquieren estos? La respuesta, aunque un tanto difusa en su concreción práctica -particularmente en lo relativo a la delimitación temporal del momento preciso de adquisición de estos rasgos (forma humana, formación de la corteza cerebral, capacidad de movimiento, viabilidad, capacidad de lenguaje, etc.)-, tiende a vincularse con nociones como la autoconciencia, la voluntad y la trascendencia. En decir, se reconduce a la tradición racionalista moderna. Sobre este punto volveremos más adelante.

En el ámbito nacional, Alejandra Zúñiga ha examinado y desarrollado algunos de estos argumentos, destacando que según las últimas investigaciones científicas, la capacidad de sentir dolor sólo se adquiere en la última parte del embarazo. Desde una perspectiva liberal, este dato permite concluir-como lo hace la autora- no sólo que el embrión no es persona (ni jurídica ni moralmente), sino que la penalización de la interrupción del embarazo (y también la sola prohibición, aunque no considere sanción penal) constituiría una limitación de la autonomía reproductiva de la mujer que sólo podría ser constitucional si no supone una carga indebida ${ }^{29}$.

La célebre sentencia norteamericana en el caso Roe v. Wade (1973) es también tributaria de una concepción liberal, si bien a menudo se le atribuye una inspiración feminista, sobreestimando la influencia que los movimientos de mujeres ejercieron en ella y perdiendo de vista los contrapuntos conceptuales desarrollados por la teoría feminista ${ }^{30}$. Con todo, la confusión en torno a la

29 ZúÑIGA, Alejandra, "Aborto y derechos humanos", Revista de Derecho de la Universidad Austral de Chile, Vol. XXIV, N 1, 2011, pp. 163-177.

${ }^{30}$ En este sentido, Owen Fiss comenta que hay muchos que ven en Roe vs. Wade un feminismo con elementos libertarios, como una libertad absoluta de las mujeres a controlar sus cuerpos. Sin embargo esta perspectiva pierde de vista que una lectura constitucional apropiada del fallo implicaría entender que el derecho a abortar de las mujeres se correlaciona finalmente con su igualdad. Fiss, Owen, " $i$ Qué es el feminismo?", Doxa 14, 1993, pp. 319-335. 
matriz ideológica de este último fallo parece derivar del cambio de dirección que el mismo imprime en el análisis, en relación con la aproximación liberal clásica. En efecto, en Roe v. Wade la Corte Suprema de EE.UU. no sólo descarta que, desde un punto de vista jurídico, el no nato sea persona sino que desplaza el foco de atención desde este eje (que ha monopolizado el debate) a los derechos de las mujeres. Retomando la metáfora de los personajes de la obra teatral, puede decirse que en el discurso del aborto, lo tradicional ha sido entender que las mujeres son las antagonistas de los embriones/fetos y que son estos últimos los que son sujetos u objetos de protección. La Corte Suprema de EE.UU., en Roe v. Wade invierte este enfoque y parte, en cambio, de la autonomía de las mujeres. Con este fallo la jurisprudencia estadounidense (que ha sufrido matizaciones importantes con posterioridad) ${ }^{31}$ se aparta de la tradición constitucional europea que pese a no suscribir, en general, la tesis de la personalidad del no nato, sigue anclada en la premisa extrajurídica de que éste constituye per se un objeto de tutela ${ }^{32}$.

El cambio de dirección planteado por Roe v. Wade es, sin duda, importante, pero no alcanza a configurar por sí solo un nuevo paradigma. Si bien la Corte Suprema de EE.UU. con este célebre fallo contribuyó a darle forma a la escurridiza subjetividad femenina, reconociendo explícitamente la autonomía reproductiva de las mujeres, lo hizo sobre la base de un expediente típicamente liberal: la comprensión de la intimidad como no interferencia. En la sección 3, a propósito de la concepción feminista de la autonomía, tendré la oportunidad de explicar con detención este matiz.

\subsection{Una crítica a la tesis de la personalidad del nasciturus en el Derecho chileno}

Este esquemático repaso del debate entre conservadores y liberales a propósito del aborto permite apuntar algunas conclusiones preliminares de cara al sistema constitucional chileno.

La tesis de la personalidad del no nato es una concepción moral que no es susceptible de reconducirse, sin más, a la tradición liberal, en la que descansa la teoría de los derechos humanos. No por casualidad, en el Derecho comparado el valor jurídico de dicha premisa se hace depender de una afirmación explícita de

31 Un detallado examen de la evolución de la jurisprudencia norteamericana en lo relativo al aborto puede encontrarse en SHAPIRO, Ian, "El derecho constitucional al aborto en los Estados Unidos: Una introducción", Doxa. N. 31, 2008, pp. 437-463.

32 Para un análisis de este tema, puede verse Rodríguez Ruiz, B., "Género en el discurso constitucional del aborto", Revista de Estudios Políticos del Centro de Estudios Políticos y Constitucionales, número 156, España, abril/junio 2012, pp. 49-83. 
las normas constitucionales en tal sentido. Es decir, de una convención establecida en los pactos fundacionales de cada sociedad. Donde esto no ocurre-esto es, en la abrumadora mayoría de los ordenamientos jurídicos-, la idea de que el no nato es persona se presenta como lo que realmente es: una posición moral que apela a creencias metafísicas y/o religiosas compartidas por un grupo considerable de individuos y rechazadas por otros tantos. Esta es la razón por la que las restricciones al aborto existentes en el Derecho comparado -y que son constitutivas de limitaciones a la autonomía reproductiva de las mujeres- se justifican, ordinariamente, sobre la protección del valor de la vida. Es decir, a título de bien constitucional, y no sobre la afirmación de un derecho a la vida del cual el nasciturus no puede -jurídicamente hablando- ser titular. Por lo mismo, tales restricciones para ser constitucionales deben satisfacer el test de proporcionalidad.

Teniendo en cuenta lo anterior resulta en extremo sorprendente que la personalidad jurídica del nasciturus se esgrima en el derecho chileno como si se tratara de una verdad inconcusa y haya llegado a transformarse en la doctrina dominante y en los cimientos para el levantamiento de un verdadero paredón que ha impedido la discusión de una reforma a la penalización radical del aborto que contempla la ley chilena. Sin ir más lejos -porque no es necesario hacerlo- recordemos que en la última década el Congreso ha rechazado en dos oportunidades la decisión de legislar para despenalizar parcialmente el aborto (en $2006^{33}$ y en 2012), arguyendo razones constitucionales. En esta última ocasión, lo ha hecho respecto de tres proyectos de ley, que tenían en común la reposición del aborto terapéutico. Dos de estos proyectos contemplaban, además, la introducción de otras indicaciones tradicionales (feto inviable en el caso del proyecto Mathei-Rossi e indicaciones eugenésica y ético-social ${ }^{34}$, en el caso del proyecto de Girardi y otros).

La renuencia del Congreso chileno a encarar la discusión sobre la flexibilización de la punición del aborto se parapeta en una supuesta incompatibili-

33 En 2006, la Cámara Baja rechazó la decisión de legislar en relación con un proyecto de despenalización del aborto presentado por Marco Enríquez-Ominami, a la sazón militante del PS, y René Alinco, del PPD.

${ }^{34}$ La indicación que el proyecto presentado, entre otros, por el Senador Girardi, califica como "indicación ético social" es un supuesto cuya denominación más apropiada es indicación criminológica. Éste permite la interrupción del embarazo cuando el embarazo es consecuencia de un hecho constitutivo del delito de violación. Este proyecto contemplaba también una indicación eugenésica, es decir, permitía el aborto en caso de que se estableciera clínicamente que el feto presenta (o presentará) graves taras o malformaciones físicas o psíquicas. Por su parte, el proyecto Mathei Rossi, además de la indicación terapéutica, contemplaba una indicación más estricta que la indicación eugenésica prevista en el proyecto anterior. Autorizaba el aborto solo en el caso de certificación médica de la inviabilidad fetal. Por último, el proyecto presentado por el senador Escalona era el más conservador de los tres. Contemplaba únicamente la reposición del aborto terapéutico en un solitario artículo que rezaba de la siguiente manera: "se podrá interrumpir el embarazo, sólo con fines terapéuticos, mediante intervención médica, cuando ésta sea documentada por dos médicos cirujanos". 
dad de una legislación de este tipo con la Constitución, para enmascarar sus componentes ideológicos. Como lo han hecho notar, entre otros, Aldunate ${ }^{35}$ y Bascuñán ${ }^{36}$, la simple utilización de los métodos gramatical, histórico y sistemático (a los que ordinariamente tiene tanto apego la dogmática constitucional chilena) revelan que ni en la letra ni en la historia de la Constitución chilena de 1980, hay rastros de la existencia de una convención que haya conferido al no nato, de manera excepcional, el estatus de persona.

Todavía más, la propia historia de la ley $N^{\circ} 18.826$ que reemplazó el antiguo art. 119 del Código Sanitario -que, como es sabido, permitía el aborto terapéutico desde la década de los 30 en Chile- demuestra que la Junta de Gobierno el año 1989 (esto es, en las postrimerías del gobierno militar) no cumplió ningún mandato programático del constituyente del 80 al modificar la referida disposición rigidizándola. Hizo, más bien, todo lo contrario: injertó una regla prohibitiva derivada de la teología moral católica (la doctrina del doble efecto que ya revisamos) que el propio constituyente había desechado, según consta en las actas respectivas. $\mathrm{Al}$ respecto el texto del proyecto de la ley $\mathrm{N}^{\circ} 18.826$ es elocuente. Dentro de sus objetivos esenciales menciona (sección II, N 5): "reemplazar la actual disposición del Código Sanitario sobre el denominado 'aborto terapéutico' por otra que exima de sanción sólo a aquellas situaciones en que se causa la interrupción del embarazo en forma indirecta e involuntaria, con un doble efecto de una acción médica necesaria desarrollada en la gestante enferma de gravedad" ${ }^{37 .}$

Cualquiera que sostenga que del mandato que el constituyente confía al legislador en orden a proteger la vida del que está por nacer (art. $19 \mathrm{~N}^{\circ} 1$ inciso $2^{\circ}$ de la Constitución) se deriva una necesaria prohibición del aborto, contradice la historia fidedigna de establecimiento de esta norma y, de paso, transgrede reglas lógicas de argumentación. Después de todo, nada indica que la única vía que el legislador tenga para promover y proteger la vida del que está por nacer sea la penalización prácticamente absoluta del aborto, más aún si -como hemos visto- la utilización de la herramienta penal no logra erradicar el aborto sino solo relegarlo a la clandestinidad. ¿Podría el legislador proteger la vida del que está por nacer a través de una adecuada política de incentivos a la maternidad? La respuesta a esta pregunta es, sin duda, afirmativa. No por casualidad las tasas de natalidad en otros países -particularmente del continente europeo- han empezado a describir una curva ascendente cuando se han elaborado y puesto en práctica políticas

\footnotetext{
35 Aldunate, Eduardo, "La titularidad de los derechos fundamentales", Estudios Constitucionales, año/ vol. 1, № 001, Centro de Estudios Constitucionales, Santiago, Chile, 2003, p. 191.

${ }^{36}$ BASCUÑán R., A., "La licitud", cit. nota n. 6, pp. 143-181.

37 Los destacados son míos. La historia completa de esta ley puede encontrarse en el sitio web del Congreso Nacional de Chile. Para un análisis crítico de la misma y de la evolución de la normativa e interpretación del aborto terapéutico en Chile, Véase BASCUÑÁN R., A., "La licitud", cit. nota n. 6.
} 
de conciliación entre la vida familiar y laboral que presuponen transferencias de subsidios estatales a las familias y fórmulas de corresponsabilidad parental.

Por último, como ya se apuntó también, la pálida duda sembrada por el Tribunal Constitucional chileno en su controvertido fallo sobre la píldora del día después, se ha esfumado tras el reciente pronunciamiento de la Corte Interamericana de Derechos Humanos en el asunto Artavia Murillo v. Costa Rica, en lo relativo al estatus del embrión en el ámbito de la Convención Americana de derechos humanos.

Aunque no he querido desaprovechar la oportunidad para aclarar estos extremos de cara al enrarecido abordaje chileno del tema (caracterizado por un pobre marco conceptual y delineado a trazos grotescamente ideológicos), creo que, incluso, si se pretendiera sobrepasar los contornos de la dogmática constitucional y se buscara arribar a una respuesta moral convincente sobre la cuestión de la personalidad del embrión/feto, ese camino -como lo anuncié al principio de este trabajo- es en sí mismo estéril.

En primer lugar -vale la pena insistir en ello-, un ensayo de esa naturaleza no es susceptible de dar origen a una propuesta jurídica que sea capaz de responder idóneamente al desafío de equilibrar distintos derechos e intereses, porque parece estar destinado a chocar contra una variedad de convicciones morales, tan diversas como innegociables. En este sentido, tengo que manifestar mi escepticismo en relación con la producción de un cambio social profundo en esta materia, a corto y mediano plazo.

En segundo lugar, un debate como el mencionado, ha tenido el efecto de eclipsar la subjetividad de las mujeres y, por extensión, los diversos derechos de los que aquellas son titulares y que están aquí ineludiblemente involucrados. En otro sitio ya he demostrado lo anterior en el marco de una crítica al fallo del Tribunal Constitucional sobre la píldora del día después ${ }^{38}$. La tutela de los derechos de las mujeres, desde luego, no puede diferirse ni ponerse entre paréntesis hasta el momento en que las sociedades arriben a un acuerdo ético-jurídico sobre el estatus del no nato, como si se tratara de un incómodo detalle.

Por último, aunque pudiera llegarse a un acuerdo en el sentido que plantean las tesis conservadoras, es decir, que admitiera la personalidad moral del embrión/feto; esto no resolvería el problema desde el punto de vista jurídico. Sólo lo recodificaría, como lo ha hecho notar Judith Jarvis Thomson. El imaginativo y célebre ejemplo del violinista de Thomson ilustra por qué esta vía no aporta por sí sola una solución sino un mero espejismo. Según Thomson, el Estado no puede exigir a las mujeres -a menos que niegue su subjetividad- Ilevar adelan-

${ }^{38}$ Bordalí, Andrés y ZúÑ̃Ga, Yanira, "Análisis del fallo del Tribunal Constitucional sobre la píldora del día después", Anuario de Derechos Humanos, Universidad de Chile, № 5, julio 2009, pp. 173-182. 
te un embarazo de nueve meses para garantizar la vida del feto, de la misma manera que no podría exigir a ninguno de nosotros que nos mantuviéramos conectados por nueve meses a un destacado violinista purificándole con nuestros riñones, por ese mismo período, su sangre; a fin de evitar que éste fallezca de una enfermedad renal ${ }^{39}$. Dicho de una manera más simple, el ordenamiento jurídico no puede exigir a los sujetos acciones heroicas ${ }^{40}$. Para ponerlo en jerga constitucional, una eventual e hipotética concesión de personalidad jurídica al nasciturus haría pasar la regulación del aborto de un problema de limitación de la libertad de unos sujetos (las mujeres) para la salvaguardia de un bien constitucional (la vida) a un problema de colisión o conflicto de derechos (entre varios titulares y, salvo el caso del aborto terapéutico, con distintos contenidos).

Conviene precisar, con todo, que mi propuesta de abandono del debate sobre la personalidad del no nato, no involucra suscribir en todos sus términos la posición liberal que aquí he descrito. Creo que esta última es susceptible de ser enriquecida y operacionalizada de mejor manera si se la matiza con las aportaciones provenientes de la teoría feminista. A esto me dedicaré en los próximos apartados.

\section{El ABORTO EN EL PENSAMIENTO FEMINISTA}

Podríamos partir esta sección preguntándonos si hay una contribución al debate sobre la mejor manera de enfrentar la regulación del aborto que provenga de la perspectiva feminista y que sea realmente original, es decir, que aporte elementos que no formen parte del registro liberal. La pregunta es pertinente porque, si bien el feminismo es referido como una ideología opinante sobre la cuestión del aborto, es habitual que los estudios dedicados al tema omitan citar a exponentes de esta línea de pensamiento, o si lo hacen, asuman que se trata de portavoces de una versión radicalizada de las tesis liberales.

Hay, al menos, tres tipos de observaciones fácticas que podrían alimentar la duda. La primera es de naturaleza histórica. Los primeros planteamientos feministas que se remontan un poco antes de la revolución francesa, abrazaron con entusiasmo el proyecto moderno liberal que prometía la aplicación a todos (incluidas las mujeres) de un cúmulo idéntico y emancipador de derechos, es decir, de una igualdad esencial humana. La segunda se relaciona con hechos más recientes. La demanda de despenalización del aborto, impulsada por los movimientos feministas, especialmente a partir de la década de los 70 del siglo

\footnotetext{
39 Thomson, Judith, "Una defensa del aborto", VVAA, Debate sobre el aborto. Cinco ensayos de filosofía moral, Editorial Cátedra, segunda edición, 1992, pp. 9-32.

40 El desarrollo de esta misma línea de análisis en relación con el Derecho penal puede encontrarse en BASCUÑáN R., "La licitud", cit. nota n. 6.
} 
pasado, se ha servido de un repertorio lingüístico asociado al espectro liberal. Así, la idea de autonomía proyectada sobre el cuerpo ha sido uno de los estandartes de este reclamo. La tercera tiene que ver con la relativa coincidencia existente entre posiciones liberales y feministas en torno a la propuesta de regulación del aborto. Ambas defienden la despenalización de éste. Aunque, como una rápida observación también arroja, la reivindicación feminista tiende a radicalizar la demanda liberal en este sentido.

Sin embargo, un examen más pormenorizado del devenir del pensamiento feminista en general y, en especial, respecto de la cuestión del aborto, revela que hace mucho tiempo que aquel se apartó considerablemente de su matriz liberal y se ha transformado en un verdadero hijo rebelde. La discrepancia fundamental entre ambas teorías se relaciona con la cuestión de los universales abstractos, admitida como piedra angular de la teoría liberal y cuestionada y reelaborada por las posiciones feministas contemporáneas. De esta gran polémica se derivan otras tantas. A los efectos de este trabajo, me parece útil rescatar, dentro de este extenso crisol, algunos elementos de la propuesta feminista de incardinación de especificidades o diferencias en la construcción de un nuevo modelo de autonomía, dado que ésta se ha desarrollado poniendo especial atención a un aspecto que resulta estratégico en el análisis sobre el aborto: la diferencia sexual.

\subsection{Autonomía y diferencia.}

\section{Una relación necesaria}

El planteamiento feminista es rico en vertientes, matices y polémicas internas. Un apretado análisis como el que aquí pretendo desarrollar está constreñido a vertebrar, de manera esquelética, una caracterización de esta corriente teórica. Con esta prevención, diré que el feminismo es una teoría sobre la emancipación que presupone una lectura sobre la desigualdad, con eje en el poder y las asimetrías de género y una correlativa propuesta para construir la igualdad a partir una comprensión y consideración adecuadas de la(s) diferencia(s). Desde luego, las ideas de sujeto, libertad, igualdad, diferencia y justicia de las que se sirve el feminismo, no sin cierta incomodidad ${ }^{41}$, aparecen también en el registro discursivo de otras tradiciones de pensamiento, como, por ejemplo, la liberal. De manera que no son un acervo exclusivo del feminismo. No obstante, tienen en la teoría feminista una comprensión compleja paradigmática.

$\mathrm{Si}$ en el liberalismo moderno el sujeto se conceptualiza como abstracto, esto es, supuestamente despojado de todo vínculo adscriptivo social (aunque

${ }^{41}$ Varias pensadoras advierten el problema que implica criticar teorías anteriores, como la liberal, sirviéndose de conceptos que han sido acuñados por dichas teorías y que han servido para excluir a las mujeres. Es decir, del uso de conceptos que estarían "contaminados". 
no del todo descorporeizado como veremos); en el feminismo no es posible la construcción de ese sujeto sin considerar la forma en que la diferencia sexualsimbolizada y normativizada por la sociedad (he aquí la noción de género) influye en ese proceso. Si en el liberalismo la igualdad se traduce en igualdad de estatus individual entre los sujetos que componen el pueblo (única pertenencia grupal relevante, a nivel político) y, por tanto, se aprecia de manera intragrupal; el feminismo admite la existencia de otras identidades adscriptivas relevantes (desde luego, la identidad sexual) y, por ende, la comprensión de la igualdad no puede hacerse al margen de las relaciones que se dan entre esos grupos, o sea, es, por definición, intergrupal. Si en el liberalismo -como viene sosteniendo Nancy Fraser- el problema de la justicia se visualiza comúnmente como la asimetría de acceso a bienes e ingresos que se repara por vía redistributiva; en el pensamiento feminista, la justicia es concebida, además, como un problema de jerarquía o estatus y se resuelve también por la vía de políticas de reconocimiento (políticas de identidad o políticas de la diferencia) orientadas a la recomposición social de estas diferencias de estatus.

Dentro de este marco conceptual, la cuestión de la capacidad reproductiva de las mujeres tiene un lugar especial en la reflexión feminista sobre la diferencia sexual y constituye un verdadero enjeu para la construcción de la justicia social. Particularmente desde la segunda mitad del siglo XX, las feministas han dedicado extensas páginas de su producción teórica a demostrar que una de las maneras que ha tenido el patriarcado (o sistema sexo/género) para asegurar su pervivencia enquistado en un modelo jurídico con vocación universalista (el modelo moderno de los derechos), ha sido a través de la "apropiación" de la capacidad reproductiva de las mujeres. Esta se ha puesto al servicio de los fines del Estado, a través de leyes y políticas que buscan controlar la gestación, el embarazo e incluso la lactancia, sustrayéndolas del ámbito de decisión individual sobre los propios proyectos y planes de vida. Así, convenientemente, la sexualidad (el cuerpo y sus pasiones) y la reproducción (incluidas las instituciones que reposan sobre ellas como la familia y el parentesco) son localizadas en un intersticio entre la moral social y lo personal, y significadas como atemporales e invariables.

Por sorprendente que parezca, el contrato sexual que subyace al pacto social moderno ${ }^{42}$ habría legitimado la sujeción de las mujeres al poder masculino, refrendado las estructuras arcaicas de sumisión de género fundadas eminentemente en la necesidad de disciplinar la capacidad femenina de "replicar" la especie humana, y/o garantizar con ello la certeza de la paternidad. Como expone Celia Amorós, desde el punto de vista simbólico, el contrato social es un mito iniciático moderno. Como todo mito fundacional legitimador permite

${ }^{42}$ La referencia es a la célebre obra de Carole Pateman, el Contrato Sexual. 
que el nuevo grupo juramentado experimente la vivencia emancipadora en tanto fratría emergente que la rescata de (re) caer en una nebulosa serial ${ }^{43}$. Desde el punto de vista antropológico, puede afirmarse plausiblemente también que la fratría original y primera fue la constitutiva del conjunto de varones, como grupo frente a la estructuración estandarizante de las mujeres y que esta estructura simbólica ha sido especialmente resistente al cambio ${ }^{44}$.

Gran parte del relativo éxito de esta empresa moderna -según las feministas- se debe a la pervivencia de la figura del sujeto abstracto. Esta se presenta, engañosamente, como sujeto asexuado, lo que ha desactivado la discusión política sobre el sexo, la sexualidad y la reproducción, y explica la falta de interés de las teorías contemporáneas sobre la justicia por problematizar a la familia. Como lo ha hecho notar particularmente Susan Moller Okin en su obra Justicia, Familia y Género ${ }^{45}$, la gran mayoría de las teorías liberales de la justicia presuponen a la familia pero no discuten ni su categorización ni las relaciones que ella abriga. En otras palabras, olvidan tratarla, al mismo tiempo que perpetúan la división tradicional de las esferas separadas. Este primer "olvido", como si se tratara de un efecto dominó, acarrea otras omisiones adicionales que son problemáticas ${ }^{46}$.

Dentro del listado de críticas de Okin, me interesa destacar aquella que expone la fragilidad del modelo de autonomía moral propuesto por el pensamiento liberal en tanto recurso epistemológico. De acuerdo a la autora si lo que busca el pensamiento liberal es reflexionar sobre la autonomía moral de los individuos, resulta forzoso analizar las condiciones fácticas de desarrollo de dicha autonomía. Y, puestos en ello, parece evidente que los seres humanos, contrariamente al punto de partida que abrazan la mayor parte

${ }^{43}$ Amorós, Celia, La gran diferencia y sus pequeñas consecuencias... para las luchas de las mujeres. Ediciones Cátedra-Universidad de Valencia, Madrid, 2006, p. 199.

${ }^{44}$ En este sentido, pueden consultarse los trabajos de Françoise Héritier sobre el sexo, el cuerpo y la reproducción desde una perspectiva antropológica. En particular, Héritier, Françoise, Masculino/ Femenino. El pensamiento de la diferencia (traducción castellana de Vicente Villacampa), Editorial Ariel, Barcelona, 1996.

${ }_{45}$ Puede consultarse su versión original en inglés: Moller Okin, Susan, Justice, Gender and the Family, Basics Books, 1989. Hay, también, una versión en francés : Molıer Okın, Susan, Justice, Genre et famille, Champs Essais, París, 2008.

46 Por de pronto, la sustracción de la familia -que se presupone situada en la esfera privada- de los criterios de imparcialidad que se aplican a lo público. Así, o se estima -aparentemente por razones de continuidad histórico-conceptual- que la familia se sitúa en el ámbito de lo privado y como tal queda fuera de la esfera de aplicación del principio de imparcialidad que regiría las relaciones situadas en lo público; o se considera que la familia por "su naturaleza" resulta regida por principios éticos diversos y más nobles que el de imparcialidad; a saber, el amor, el altruismo, la abnegación, la solidaridad, etc. Esta última lectura -es útil advertirlo- constituye una reedición contemporánea de la vieja idea de "complementariedad de los sexos". 
de las teorías liberales, no nacen adultos ni autónomos, sino que crecen y arriban a la madurez gracias a la atención y a la ardua labor suministradas, fundamentalmente por las mujeres, en el contexto de las relaciones familiares. La perspectiva moderna liberal del "hombre hongo" -como la ha bautizado el feminismo- es, por tanto, claramente contrafáctica. Metamorfoseada en posturas como la del velo de la ignorancia de Rawls, no promete más que pasar de la ceguera a la miopía, y sus consecuencias morales son también deficitarias. A propósito de su crítica al modelo rawlsiano de justicia, la propia Okin ha proporcionado una exquisita caricatura: Tres jueces ancianos y de toga aparecen mirando hacia abajo, y ven con asombro sus vientres de un embarazo avanzado. Uno dice a los otros dos, sin más detalles: Tal vez sería mejor reconsiderar esta decisión. Lo que busca poner de relieve Okin con esta caricatura es que la reflexión sobre la justicia se viene construyendo de espaldas a la nutrida evidencia que demuestra que los planes de vida de los individuos están profundamente atravesados por el sistema sexo/género, al punto que la propia libertad de estos individuos se pone en entredicho.

Catharine MacKinnon ha desarrollado con agudeza esta línea crítica, respecto del aborto. Mackinnon observa que los liberales han respaldado la posibilidad de elegir el aborto a través de una interpretación de la intimidad como libertad no interferencia, con la idea implícita de que el control de la reproducción es necesario para la libertad sexual y la independencia económica y advierte que, tanto liberales como conservadores, comparten la presunción tácita de que las mujeres casi siempre controlan el sexo. Sin embargo -pregunta MacKinnon- si un "no" puede tomarse como un "si", ¿ ¿hasta qué punto puede ser libre el "si"? El problema de la aproximación liberal del aborto, según la jurista estadounidense, es que nunca ha sido enfocada explícitamente en el contexto de cómo se quedan embarazadas las mujeres y, por tanto, nunca ha considerado que el embarazo es consecuencia de un coito que se realiza en condiciones de desigualdad entre los sexos y que tiene mucho, entonces, de sexo forzado. En opinión de MacKinnon la doctrina privada de la intimidad no es una herramienta conducente a la emancipación de las mujeres porque la desigualdad genérica que subyace a la libertad sexual no libera sexualmente a la mujer tanto como libera la agresión sexual del hombre ${ }^{47}$.

Tamar Pitch advierte, por su parte, que la argumentación "prochoice" distorsiona la autonomía moral de las mujeres al sujetarla a los parámetros del individualismo contractualista abstracto, hipervoluntarista y calculador. En esta nueva obra teatral las mujeres aparecen como arrogantes protagonistas que

${ }^{47}$ Cabe recordar que Mackinnon es una de las promotoras más encarnizadas de la prohibición de la pornografía. En lo relativo al aborto, véase MACKInNon, Catharine, Hacia una teoría feminista del Estado, Ediciones Cátedra-Universidad de Valencia. Madrid, 1995, pp. 329-348. 
sacrifican no sólo los intereses de los fetos sino también de los varones-padres los que devienen, ahora, nuevas víctimas ${ }^{48}$.

De ahí que, con importantes matices, Okin, Mackinnon, Pitch, Benhabib ${ }^{49}$, Phillips $^{50}$, Fraisse ${ }^{51}$ y otra larga lista de teóricas feministas vengan sosteniendo con insistencia que la articulación liberal moderna y contemporánea de la autonomía, con eje en el sujeto abstracto, no es útil como único criterio para la atribución igualitaria de derechos. Al contrario, ha sido un obstáculo para la construcción de la subjetividad de las mujeres en la medida de que éstas siguen siendo simbolizadas como un remedo o negativo de esta figura.

Esta crítica, de nuevo, es especialmente certera en lo concerniente al aborto. La forma cómo el pensamiento conservador se ha servido de la idea moderna de sujeto, radicalizando su abstracción para hacerla extensiva al nascituris y excluyendo, en contrapartida, los derechos reproductivos de las mujeres; demuestra que una concepción de autonomía como la moderna, difícilmente puede cimentar la tutela de los intereses femeninos. Entre nosotros, el artículo de Jorge Fábrega, en el que retoma la tesis de Michael Tooley que apunta a la dificultad de establecer, a partir de un modelo conceptual como el referido, fronteras nítidas que justifiquen la diferencia de tratamiento del aborto y el infanticidio ${ }^{52}$, es un buen ejemplo de lo que aquí comento. A partir de esta tesis, el autor de este trabajo termina transfiriendo la carga de justificación a las tesis defensoras del aborto y concluyendo que los derechos abortivos de las mujeres deben ser reevaluados ${ }^{53}$.

Creo que, a estas alturas, se puede concluir que un concepto de autonomía enraizado en el sujeto abstracto tiene, un potencial emancipador limitado, debido a que ha sacralizado un modelo bifronte y generalmente contradictorio de relaciones. Así, las relaciones que se desarrollan en la esfera pública son

${ }^{48}$ Piтch, Tamar, Un derecho para dos. La construcción jurídica del género, sexo y sexualidad, Trotta, Madrid, 2003. En especial, el capítulo 2 dedicado al aborto, pp. 75-120.

49 Puede verse BenhabiB, Seyla, El ser y el Otro en la ética contemporánea. Feminismo, comunitarismo y postmodernismo, Gedisa, Madrid, 2006.

${ }^{50}$ Véase PHILLIPS, Anne, "Las pretensiones universales del pensamiento político" en Barrett, M. Phillips, A. (Eds.) Desestabilizar la teoría. Debates feministas contemporáneos, Programa Universitario de Estudios de Género UNAM-Paidós, México DF, 2002, pp.24-44.

51 Véase FraISSE, Geneviève, Musa de la Razón, Ediciones Cátedra-Universidad de Valencia, Madrid, 1991, y de la misma autora Los dos gobiernos: la familia y la ciudad, Ediciones Cátedra-Universidad de Valencia, Madrid, 2003.

52 Tooley, Michael, "Aborto e infanticidio", VVAA. Debate sobre el aborto. Cinco ensayos de filosofía moral, Ediciones Cátedra, pp. 69-107.

53 FÁ́rReGa, Jorge, "El aborto y los límites de la autonomía", Estudios Públicos, 128, primavera 2012, pp. 61-87. 
desplazadas hacia el terreno de la historicidad y la cultura siendo susceptibles de renegociarse a la luz de las exigencias de los principios de imparcialidad, libertad e igualdad. Mientras que las relaciones que se desarrollan en la esfera privada, es decir, en la esfera de la reproducción y el cuidado; son catalogadas como atemporales e invariables y quedan regidas por principios éticos diferentes e incluso opuestos (el amor, la abnegación, el sacrificio, etc.).

Como vimos en la primera parte de este trabajo, esta cartografía conceptual permite derivar de la capacidad reproductiva de las mujeres (que es biológica) una batería de consecuencias socio-normativas. Entre otras, la exigencia de que la defensa de la vida e intereses del no nato se haga a expensas del sacrificio de los intereses de la madre (incluida, en algunas posturas, su propia vida); o que el apego madre-hijo deba iniciarse durante el embarazo, proyectarse a la lactancia y al cuidado posterior de los hijos. Debido a su capacidad procreativa, las mujeres son arrastradas en permanencia hacia la tierra de las emociones, condenadas a repetir los ciclos naturales e infantilizadas para que, en ejercicio de su supuesta libertad, no se dañen a sí mismas o a otros sujetos ${ }^{54}$. Esta infantilización está presente incluso como subtexto de algunas propuestas a favor de la despenalización del aborto en las que la interrupción del embarazo es descrita siempre como una tragedia para las mujeres y el aborto es simbolizado prevalentemente como un problema social (socioeconómico y/o criminológico).

Lo anterior ha llevado a afirmar a las teóricas feministas que el pensamiento liberal hegemónico ha sido incapaz de elaborar una teoría que recoja adecuadamente la forma en que el poder y la dominación se correlacionan con la diferencia sexual, y de construir, en consecuencia, tipos específicos de sujetos.

Podríamos preguntarnos si, atendidas las dificultades que la articulación de un concepto satisfactorio de autonomía ha presentado para un variado repertorio teórico (liberales, comunitaristas, multuculturalistas etc.) no sería mejor prescindir de él. Lo anterior, aunque tentador, no parece viable porque la autonomía está íntimamente vinculada con otros tantos valores y se irradia al conjunto de los derechos. Pero, por lo mismo, urge contar con un concepto que sea funcional, es decir, que permita construir teorías y desarrollar propuestas normativas adecuadas.

${ }^{54}$ Blanca Rodríguez Ruiz, comentando la regulación constitucional del aborto a nivel comparado, advierte que esta construcción de género está detrás de los discursos que urgen al ordenamiento jurídico a proteger a las mujeres frente a sus propias decisiones, apelando a su irracionalidad, necesidad de cuidado o destino natural. Véase Rodrícuez Ruiz, Blanca, "Género en el discurso", cit. nota 32. En el caso chileno, hemos podido apreciar este repertorio discursivo de cerca en las discusiones que rodearon la creación del postnatal parental y los proyectos recientes de despenalización parcial del aborto. En el primer caso, se justificó la irrenunciabilidad parcial del permiso postnatal parental sobre la base de la protección de la mujer en la relación laboral y en el segundo caso, se apeló a la necesidad de proteger a las mujeres del síndrome post-aborto. 
Un concepto de la autonomía fuertemente anclado en la racionalidad ya no es suficiente, debido principalmente a su incompletitud. No es ni siquiera una buena explicación descriptiva de los seres humanos (los sujetos no son sólo seres racionales sino también emocionales) y tampoco es de utilidad prescriptiva porque en muchos ámbitos ligados a los proyectos de vida de los individuos -como los que aquí hemos revisado- se requiere una idea normativamente más rica y que tenga en cuenta el contexto en el cual las personas se mueven y ejercen esta capacidad. Es decir, se requiere de una noción que sea capaz de sintetizar las condiciones de inter-dependencia creadas por una superposición de identidades socialmente construidas (la diferencia sexual, la raza, la clase, la orientación sexual, etc.).

Como es obvio, entonces, el desafío feminista ha sido tratar de elaborar una propuesta alternativa de autonomía que pueda superar el sesgo liberal y transformarse en un criterio útil para la efectiva individuación de las mujeres. Ésta se ha caracterizado por su énfasis en la diferencia, especialmente, la diferencia sexual.

Uno de los caminos preferidos por el feminismo para poner en práctica este esfuerzo ha consistido en la problematización del cuerpo ${ }^{55}$. Este camino se ha revelado pedregoso para la teoría feminista, Ilegando a fragmentarla en varias posturas. Sin embargo, creo que, particularmente en el marco de los debates sobre el aborto, la aproximación feminista sobre el cuerpo es mal entendida o aparece deformada como propietarización. Por eso me interesa aclarar este punto.

El análisis feminista sobre el cuerpo discurre más en clave de autonomía (por ejemplo, la idea de representación del ser sexuado en Drucilla Cornell ${ }^{56}$ o la paridad participativa de Nancy Fraser ${ }^{57}$ ), que en clave de propiedad del cuerpo (al estilo de Locke o Nozick). En otras palabras, el análisis feminista sobre el cuerpo parte de la premisa de que éste es un escenario de poder ( $y$, por tanto, una cuestión política), continente de la triada sexo-sexualidad-procreación. El objetivo de esta propuesta es liberar a las mujeres del cuerpo sexuado, en el entendido de que, tal como éste ha sido concebido, las encamisa en una normatividad de lo femenino (la ideología de la maternidad) que se caracteriza por simbolizar la sexualidad como dirigida siempre a la procreación. De

\footnotetext{
${ }^{55}$ En este esfuerzo, las teóricas feministas no han estado solas. Muestra de ello es la proliferación reciente de trabajos sobre el cuerpo en la que, sin duda, ha influido determinantemente la atención que Foucault prestara a este asunto, en sus tres volúmenes sobre la Historia de la sexualidad.

${ }^{56}$ Cornelt, Drucilla, El corazón de la libertad, Feminismo, sexo e igualdad, Ediciones Cátedra-Universidad de Valencia, Madrid, 2001.

57 Fraser, Nancy y Honeth, Axel, ¿Redistribución o reconocimiento?, Ediciones Morata - Fundación Paideia, Madrid, 2006.
} 
ahí que buena parte del análisis feminista busque resignificar positivamente el erotismo y el placer.

Desde luego, en el marco de las propuestas feministas posmodernas y de la teoría queer ${ }^{58}$ este esfuerzo de deconstrucción del cuerpo puede ir más allá y suponer una verdadera soberanía sobre el mismo que permite subyugarlo, transformarlo y amoldarlo a la voluntad de los sujetos, lo que, de paso, ha sido pavimentado con los avances científicos. En cualquier caso, y más allá de estas ramificaciones -que me parecen también sugestivas de cara a las recientes reformas jurídicas sobre la materia a nivel comparado- el gran mérito de la aproximación feminista sobre el cuerpo es que ofrece herramientas para "ponerlo entre paréntesis" o "desbiologizarlo", en un registro radicalmente universalizante. Es decir, hace extensivo a todos los sujetos una dimensión estratégica de la autonomía que, hasta ahora, ha sido un privilegio de los varones heterosexuales. En efecto, sólo los hombres heterosexuales han podido construir sus proyectos de vida de una manera no mediada por su sexo y su ejercicio de la sexualidad no ha sido simbolizado (como sí ha ocurrido con las mujeres y con las personas con una orientación distinta a la heterosexual) como únicamente dirigido a la procreación.

En resumen, la teoría feminista sobre la autonomía, que se correlaciona con sendas propuestas sobre la igualdad y la justicia, y que hemos revisado a partir de una síntesis apretada de su polémicas con el pensamiento liberal, es una concepción compleja que parte del sujeto sexuado y, por tanto, situado en un entramado de relaciones sociales que van desde lo simbólico a lo institucional. A diferencia de la propuesta comunitarista -hay que precisar- el sujeto feminista no se diluye en la comunidad y en las tradiciones, sino que sigue singularizado. En consecuencia, la autonomía para el feminismo es la posibilidad de elección concreta desde quién se es con miras a devenir quien se desea ser.

Proyectada esta versión de autonomía hacia la cuestión del aborto, supone una afirmación de la competencia moral de las mujeres para tomar decisiones en materia procreativa, y el consiguiente rechazo a las regulaciones punitivas que niegan tal competencia y que simbolizan los cuerpos de las mujeres como meras incubadoras. Para el feminismo, el reconocimiento de la autonomía moral de las mujeres implica la afirmación del valor intrínseco de las opciones que éstas realizan libremente y, específicamente, de la opción de ser madres (incluido el momento y las condiciones en que eso se materializa) como de la decisión de no serlo.

${ }^{58}$ En esta línea de análisis, sobresalen los influyentes trabajos de Judith Butler. En especial, BuTLER, Judith, El género en disputa. El feminismo y la subversión de la identidad. (Traducción de María Antonia Muñoz). Paidós, Barcelona, 2007, y BuTLER, Judith, Deshacer el género, Editorial Paidós, Barcelona, 2006. 
Dado que hay pocas cosas como la maternidad que incidan tan profundamente sobre el plan de vida de una mujer, la autonomía procreativa no implica simplemente una decisión sobre el cuerpo, sino, más bien, una decisión que atraviesa los proyectos de vida de cada mujer. No por casualidad, el pensamiento feminista ha trazado diversos puentes entre la esfera privada (reproducción y cuidado) y la pública (política y trabajo remunerado) que han dado forma a gran parte del acervo explicativo contemporáneo de fenómenos aparentemente inconexos como la baja presencia de mujeres en puestos de representación política o las brechas salariales entre hombres y mujeres.

Así las cosas, la discusión sobre el aborto es necesariamente una discusión sobre la autodeterminación que debe partir de una reflexión sobre las condiciones fácticas en que el sexo, la sexualidad y la reproducción se desarrollan e interactúan. Dicho de otra manera, la discusión sobre el aborto reenvía a otra discusión más amplia que el Derecho moderno ha rehuido por mucho tiempo: la relación entre el cuerpo y el sujeto.

Como hemos visto aquí, el cuerpo femenino es, al mismo tiempo, un escenario complejo de poder (continente del poder biológico de la reproducción y de las fuerzas sociales que intentan disciplinarlo) como un terreno de individuación. Esa es la razón por la que en la agenda política feminista el reconocimiento del control sobre la sexualidad y la procreación resulta tan estratégica para la vertebración de la igualdad.

La relación cuerpo-sujeto tiene variadas repercusiones y algunas de ellas se proyectan también sobre el vínculo entre la madre y el embrión/feto. Como apunta Pitch, el vínculo entre la madre y el embrión/feto no es susceptible de construirse ni en términos de propiedad ni como una relación entre dos sujetos autónomos. Antes bien, se trata de una relación simbiótica en la que la posibilidad misma de desarrollo físico y psíquico de uno está inextricablemente entrelazada con el cuidado, el deseo y el imaginario de la otra ${ }^{59}$. De ahí que la protección de los intereses de uno no pueda realizarse al margen de la protección de los intereses de la otra.

Veamos, entonces, sobre qué elementos podría concretarse una propuesta normativa, de inspiración feminista, sobre la mejor manera de abordar las decisiones en materia reproductiva, y que pueda servir de base para una regulación de este tema en Chile.

\subsection{Una cartografía feminista para la regulación del aborto en Chile}

Una propuesta feminista sobre el aborto podría ser relativamente variopinta desde el punto de vista de su manera de conciliar, en la práctica, la autodeter-

${ }^{59}$ PiтcH, Tamar, Un derecho para dos, cit. nota n. 48, p. 97. 
minación procreativa con la tutela del valor de la vida. Por lo mismo, más que ensayar reglas específicas y detalladas que regulen esta cuestión, mi propósito aquí es referir cuáles debieran ser sus ejes conceptuales básicos. En otras palabras, quiero bosquejar una cartografía feminista sobre este asunto, alternativa a la que revisamos a propósito del debate en torno a la personalidad del no nato y que pueda servir de base a una reforma a la actual regulación del aborto en Chile, o al menos, al surgimiento de una interpretación constitucional más adecuada.

En primer lugar, una propuesta feminista sobre la regulación del aborto será -como es obvio- siempre crítica de las normativas e interpretaciones que nieguen a las mujeres la calidad de sujetos dotados de autonomía moral. La forma en que se ha justificado recientemente la negativa a discutir una reforma a la estrechísima regulación del aborto terapéutico en Chile, es testimonio de que, en realidad, las mujeres no somos simbolizadas como sujetos en el sistema chileno. Como se puede comprobar a partir de un simple repaso de prensa, parte de las ideas maestras que justificaron esta renuencia giraron en torno a la negación de la existencia de un alto riesgo o peligro para la vida de la madre y/o la afirmación de que, en la práctica, tal hipótesis (el aborto terapéutico) estaría, en realidad, permitida. Las declaraciones del ministro de Salud-Jaime Mañalich-ilustran este enfoque. El titular de salud aseveró repetidamente que no es necesario legislar sobre el aborto porque "hoy día a las mujeres que tienen riesgo de vida por continuar un embarazo, la doctrina médica, moral ética es clara y el ejemplo más reiterativo es el embarazo tubario, donde en todos los casos se ha actuado en favor de la madre aunque eso ha significado la interrupción del embarazo" (La Tercera, 22.03.12).

Este argumento que varios políticos y columnistas presentaron como contundente, tiene dos graves defectos. En primer lugar, sustrae la discusión sobre el aborto de la deliberación pública que, como sabemos, en los sistemas democráticos se radica en las instituciones representativas; y la entrega, en contrapartida, a la decisión de un gremio. Desde una perspectiva política, supone una clara regresión. Y, en segundo término, minusvalora la protección de la vida y salud de las mujeres dado que pone ésta en una situación más precaria que la protección de otros derechos. Voy a explicar este punto mediante la extensión del mismo argumento a la garantía de otros derechos.

Suponga el lector, por ejemplo, que el Ministro de Justicia le dice a usted que no es necesario que la ley garantice su derecho de propiedad porque la gran mayoría de las personas no tiene el hábito de robar, según demuestran todas las estadísticas delictuales. Seguramente, usted pensará que el valor que usted mismo y la sociedad le asignan a la propiedad privada, justifican que la ley garantice su protección, incluso si el riesgo de atentado a este derecho es estadísticamente menor que su respeto espontáneo, por parte de los otros 
sujetos. No encuentro ninguna razón que justifique que la protección de la vida de las mujeres reciba un tratamiento distinto, esto es, quede entregada al respeto espontáneo de otros sujetos, por mucho que se trate de profesionales de la salud.

Al contrario, hay sobradas razones para afirmar que la falta de regulación legal del aborto terapéutico acrecienta el riesgo de lesión del derecho a la vida, salud e integridad físico-psíquica de las mujeres. La sentencia de la Corte Europea de Derechos Humanos que condena a Polonia por no aplicar su propia normativa de despenalización de aborto terapéutico (RR c. Polonia, 26.05.11), el dictamen del Comité de Derechos Humanos contra Perú (№ 1153/2003), así como las dificultades identificadas por la Corte Suprema argentina en su reciente fallo de 2012 (F.A.L /medida autosatisfactiva), traducidas en una reiterada, innecesaria e ilegal "práctica institucional" de judicialización de las solicitudes de aborto legal ${ }^{60}$, demuestran que aun cuando es una ley la que garantiza un procedimiento para que las mujeres accedan a la interrupción del embarazo en supuestos de riesgo para su vida o salud, es posible que la intervención de facultativos con convicciones morales contrarias al aborto u otros agentes, obstaculice la protección de tales derechos. Desde luego, esta evidencia contradice la confianza que el ministro Mañalich y otros actores políticos depositan en el gremio médico, incluso en los casos en que es la propia ley -y no un código deontológico interno- la que mandata la protección prevalente de la vida o salud de la madre, si resultan amenazadas por la continuación de un embarazo.

La oposición a legislar sobre el aborto terapéutico encubre, entonces, un rechazo a la individuación de las mujeres. En efecto, las define como seres incapaces de tomar decisiones sobre su propia vida y salud, y transfiere, por consiguiente, esas decisiones al Estado o a otros sujetos. Reparar este agravio por la vía de la ampliación de la indicación terapéutica y de la regulación de un procedimiento que salvaguarde adecuadamente dichos derechos, es, por tanto, urgente.

Con todo, una normativa en la dirección apuntada es condición necesaria pero no suficiente para la individuación jurídica de las mujeres chilenas. Se requiere, además, avanzar a una regulación del aborto que reconozca la autonomía de las mujeres en relación con las decisiones procreativas y que abandone la idea de que los derechos de estas y otros intereses en juego (como la vida del que está por nacer) son unidades aislables de los contextos sociales de interdependencia en los se desenvuelven los sujetos y en los que se proyectan tales decisiones.

${ }^{60}$ Toda esta jurisprudencia es referida en la primera parte de este trabajo. Véase, en particular las notas números 5 y 9 . 
Una aproximación como la que propongo aquí, excluye, por ende, todo planteamiento normativo que codifique el aborto como una lucha antagónica entre la madre y el feto, respecto de la cual el Estado tiene que tomar partido por el más débil, haciendo uso de su herramienta más poderosa: el castigo penal. Como advertí antes, tal esquema analítico, permite hacer hueco a la ideología de la maternidad y coloca, a menudo, a las mujeres que deciden interrumpir un embarazo en la posición de agresoras. Una lectura antagónica del aborto, omite considerar que la maternidad es un proyecto comúnmente valorado por las mujeres y que, siendo así, la decisión de interrupción de un embarazo está ordinariamente ligada a factores que difícilmente pueden calificarse como caprichosos. A saber, la incompatibilidad con otros proyectos de vida valiosos, la afectación de otros derechos como la propia vida, la falta de control respecto de la propia sexualidad (como en el caso del embarazo producto de una violación) o la falta de viabilidad del propio proyecto de maternidad (como en los casos de inviabilidad fetal). Sin embargo, sería igualmente simplista -como desmenuza Veggetti- pensar que la mujer que aborta, necesita hacerlo; no elige, no juzga. Sería no hacer justicia a esa inteligencia de la maternidad que nos esforzamos en movilizar e implicaría tratar a la mujer gestante como una verdadera incapaz. Si hay una confrontación en el aborto es aquella que se desarrolla en la propia psiquis de las mujeres, entre fuerzas promotoras y fuerzas negadoras de la maternidad, que termina resolviéndose de manera favorable a estas últimas ${ }^{61}$.

Abordar esta variada tipología de una manera estandarizada y dicotómica no parece adecuado desde una perspectiva de los derechos compatible con un modelo situado de la autonomía. En muchos sentidos, la propuesta feminista sobre la autonomía implica un desafío que excede a la regulación del aborto y reenvía a cuestiones más amplias como la comprensión y praxis de los derechos. Implica reformular la idea de que los derechos son portadores de una concepción estática de protección del más débil haciéndola permeable a los fenómenos sociales de interdependencia, que afectan especialmente a las mujeres y las constituyen en una identidad genérica, pero que, al mismo tiempo, las individualizan en función de sus propias especificidades. La clave de un concepto de autonomía situado es reconocer no sólo las semejanzas genéricas sino también las diferencias que distinguen a las mujeres entre sí. Retomaré este punto más abajo, a propósito de la concreción de mi propuesta normativa.

El enfoque antagónico feto/madre es también simplista desde la perspectiva del rol del Estado, porque omite considerar seriamente las obligaciones de

${ }^{61}$ VeGGetl, Silvia, "El aborto, una derrota del pensamiento", Debate Feminista, año 10, vol. 20, 1999, pp. 96-101. 
éste respecto de los sujetos e intereses implicados. Parece difícil admitir que el compromiso del Estado con la individuación de las mujeres en el marco de una concepción fuerte y exigente de la autonomía pueda traducirse sencillamente en la mera prohibición de interferencia o, peor aún, en la actividad de un Estado gendarme. Este déficit normativo puede apreciarse tanto en regulaciones permisivas de la interrupción del embarazo, como en sus antípodas, esto es, en las respuestas punitivas absolutas. Tomemos un ejemplo de cada uno de estos tipos: la regulación en Roe $v$. Wade y la regulación chilena.

Recordemos que la tesis central de la Corte Suprema de EE.UU. en dicho fallo, incardina la decisión sobre interrupción voluntaria del embarazo en un derecho no interferencia (la intimidad), sin perjuicio de reconocer un legítimo interés del Estado en proteger la vida del feto, a partir del tercer mes de gestación. Esta aproximación parece, en principio, compatible con la autonomía de las mujeres. No obstante, ni aquí ni en fallos posteriores la Corte Suprema norteamericana se preocupa por reflexionar seriamente sobre las obligaciones positivas que debieran correlacionarse con tal interés estatal en proteger la vida emergente. Dichas obligaciones suponen ir más allá de la sola prohibición de interferencia. Implican la producción de un contexto socio-jurídico amable con el embarazo y la maternidad, que permita que las mujeres que optan por este proyecto -o incluso aquellas que están constreñidas a llevarlo a cabo-, lo hagan de una manera acorde con el desarrollo de otros proyectos, definidos por ellas - de manera individual-como tan o más valiosos. En Roe v. Wade, en cambio, el interés de proteger la vida del feto se limita a obligar a las mujeres gestantes, después del primer trimestre, a llevar a término sus embarazos; desentendiéndose de los costos y cargas que esto conlleva.

Por su parte, la manera cómo el legislador nacional ha resuelto concretar el mandato constitucional de protección de la vida del que está por nacer, no difiere demasiado de este planteamiento, pese a que -como hemos visto-, en el caso chileno ha supuesto, además, una interpretación favorable a la subjetivación del nasciturus. La regulación punitiva chilena se traduce también en la sola imposición de la gestación completa a las madres sin involucrar el establecimiento de una política de promoción y protección de la maternidad, que sea coherente con el estatus privilegiado que, en la óptica chilena, se le acuerda a la vida del no nato.

Visto todo lo anterior, creo que una política de regulación del aborto compatible con el modelo de autonomía propuesto por el feminismo, desde el punto de vista práctico, debiera articularse de una manera multidimensional.

En primer lugar, debiera partir de una orientación preventiva más que punitiva. Para ello es necesario vertebrar una política basada en una educación sexual robusta y un adecuado suministro de medios anticonceptivos, combinada con una política de incentivos a la maternidad que considere subsidios y ayudas a 
las madres, por una parte, y que vertebre un modelo de corresponsabilidad, en lo concerniente a las responsabilidades parentales de cuidado, por la otra.

En segundo lugar, en el caso de embarazos no deseados, es preciso establecer una legislación permisiva del aborto a través de un modelo de plazos que permita a cualquier mujer decidir autónomamente proseguir o interrumpir su embarazo, dentro de un determinado período. La determinación de este período, con todo, debe estar enlazada a condiciones fácticas que garanticen un adecuado desarrollo de la autonomía procreativa en contextos diversos. Requiere, en consecuencia, prestar especial atención a la configuración sociodemográfica de cada comunidad jurídica. En este sentido, podría no ser razonable restringir el plazo para abortar a las primeras 12 semanas de la gestación (regla relativamente extendida en el derecho comparado) en aquellas sociedades en las que las condiciones de ruralidad y/o la carencia de cobertura sanitaria apropiada dificulten el diagnóstico temprano del embarazo y/ o el acceso igualitario a procedimientos de salud que garanticen la interrupción segura del mismo. Mucho menos si este plazo se combina con mecanismos de consejo y/o tiempos de reflexión, administrados a través de estructuras burocráticas, dado que tales mecanismos ralentizan la adopción y puesta en práctica de la decisión de abortar.

En tercer lugar, los mecanismos antes referidos, es decir, de consejo y/o tiempos de reflexión, que podrían legitimarse -como lo hace el derecho comparado- a partir del interés estatal en la protección del valor de la vida, deben condicionarse estrictamente al principio de neutralidad en la entrega de la información, para evitar los intentos de "disciplinar" por esta vía la decisión de cada mujer.

Finalmente, este régimen debe complementarse con un sistema de indicaciones que permita interrumpir el embarazo, por encima del período general, en el caso de que se presenten ciertas indicaciones especiales. Aunque el listado de indicaciones podría ser más o menos amplio, según las características de cada sociedad, existe un núcleo duro de indicaciones imprescindibles, dado que su omisión puede implicar la violación de otros derechos, como se ha apuntado previamente. Estas son la indicación terapéutica (riesgo para la vida y salud físico-psíquica de la madre), la indicación eugenésica (falta de viabilidad y graves malformaciones fetales) y la indicación criminológica (embarazo resultado de violación).

\section{BibLIOGRAFÍA}

AldunAte, Eduardo, "La titularidad de los derechos fundamentales", Estudios Constitucionales, año/vol. 1, No 001, Centro de Estudios Constitucionales, Santiago, Chile, 2003, pp. 187-201. 
Amorós, Celia, La gran diferencia y sus pequeñas consecuencias... para las luchas de las mujeres, Ediciones Cátedra-Universidad de Valencia, Madrid, 2006, p. 199.

BADINTER, Elizabeth, La mujer y la madre. Un libro polémico sobre la maternidad como nueva forma de esclavitud (traducción de Montse Roca), La esfera de los libros, Madrid, 2011.

Bascuñán R., A., "La licitud del aborto consentido en Chile", Revista Derecho y Humanidades, № 10, 2004, pp. 143-181.

BenHabib, Seyla, El ser y el Otro en la ética contemporánea. Feminismo, comunitarismo y postmodernismo, Gedisa, Madrid, 2006.

BYRNES, Andrew, "El uso de las normas internacionales de derechos humanos en la interpretación constitucional para el adelanto de los derechos humanos de las mujeres", Facio, Alda y Fries, Lorena. (Eds.) Género y Derecho, LOM Ediciones/La Morada, Santiago de Chile, 1999, pp. 325-406.

BORDALí, Andrés y ZúÑ̃IGA, Yanira, "Análisis del fallo del Tribunal Constitucional sobre la píldora del día después", Anuario de Derechos Humanos, Universidad de Chile, N 5, Julio 2009, pp. 173-182.

BUTLER Judith, Deshacer el género, Editorial Paidós, Barcelona, 2006.

BUTLER Judith, El género en disputa. El feminismo y la subversión de la identidad (Traducción de María Antonia Muñoz), Editorial Paidós, Barcelona, 2007.

Carpizo, Jorge y Valadés, Diego, Derechos humanos, aborto y eutanasia, Universidad Nacional Autónoma de México, México, 2008.

CASAS, Lidia, Mujeres procesadas por aborto, Foro Abierto de Salud y Derechos Reproductivos, Santiago, 1996.

Cook, R., "Leyes y políticas sobre el aborto: retos y oportunidades", Debate feminista, marzo 1991, pp. 89-129.

Cornell, Drucilla, El corazón de la libertad, Feminismo, sexo e igualdad, Ediciones Cátedra-Universidad de Valencia, Madrid, 2001.

DwOrkIN, Ronald, El dominio de la vida: una discusión sobre el aborto, la eutanasia y la liberal individual, Editorial Ariel, Barcelona, 1993.

FÁbrega, Jorge, "El aborto y los límites de la autonomía", Estudios Públicos, 128, primavera 2012, pp. 61-87.

Fernández Valle, Mariano, "El debate legal sobre aborto en la Argentina: avances, reacciones y perspectivas", Género, sexualidades y derechos humanos, Revista Electrónica Semestral del Programa Mujeres, Género y Derechos Humanos. Vol. I, Nº 1., enero 2013, pp.19-24.

Ferrajoli, Luigi, "La cuestión del embrión: entre el derecho y la moral", Revista de la Facultad de Derecho de México, No 245, 2006, pp. 255-275. 
Figueroa, Rodolfo, "Concepto de persona, titularidad del derecho a la vida y aborto", Revista de Derecho de la Universidad Austral de Chile, Vol, XX, $N^{\circ}$ 2, diciembre 2007, pp. 95-130.

FinNIs, John, "Pros y contras del aborto", VVAA, Debate sobre el aborto. Cinco ensayos de filosofía moral, Ediciones Cátedra, Madrid, 1992, pp. 108-142.

FIss, Owen, "¿Qué es el feminismo?", Doxa 14, 1993, pp. 319-335.

FraISSE, Geneviève, Musa de la Razón, Ediciones Cátedra-Universidad de Valencia, Madrid, 1991, y de la misma autora, Los dos gobiernos: la familia y la ciudad, Ediciones Cátedra-Universidad de Valencia, Madrid, 2003.

Fraser, Nancy y HONeth, Axel, ¿Redistribución o reconocimiento?, Ediciones Morata - Fundación Paideia, Madrid, 2006.

García Pascual, Cristina, "Cuestiones de vida y muerte. Los dilemas éticos del aborto", Derechos y Libertades, Número 16, Época II, enero de 2007, pp. 181-209.

Héritier, Françoise, Masculino/Femenino. El pensamiento de la diferencia (traducción castellana de Vicente Villacampa), Editorial Ariel, Barcelona, 1996.

Htun, Mala, Sexo y Estado. Aborto, divorcio y familia bajo dictaduras y democracias en América Latina, Ediciones Universidad Diego Portales, Santiago (Chile), 2010.

Lagarde, Marcela, Los cautiverios de las mujeres. Madresposas, monjas, putas, presas y locas, Horas y Horas la Editorial, Madrid, 2011.

MacKinnon, Catharine, Hacia una teoría feminista del Estado, Ediciones CátedraUniversidad de Valencia, Madrid, 1995, pp. 329-348.

Moller Orin, Susan, Justice, Genre et famille, Champs Essais, París, 2008.

NarI, Marcela, Políticas de maternidad y maternalismo político, Editorial Biblos, Buenos Aires, 2004.

PHILLIPS, Anne, "Las pretensiones universales del pensamiento político" en Barrett, M. Phillips, A. (Eds.) Desestabilizar la teoría. Debates feministas contemporáneos, Programa Universitario de Estudios de Género UNAM-Paidós, México DF, 2002, pp. 24-44.

PाтсH, Tamar, Un derecho para dos. La construcción jurídica del género, sexo y sexualidad, Trotta, Madrid, 2003.

Rodríguez Ruiz, B., "Género en el discurso constitucional del aborto", Revista de Estudios Políticos del Centro de Estudios Políticos y Constitucionales, número 156, España, abril/junio 2012, pp. 49-83.

SHAPIRO, Ian, "El derecho constitucional al aborto en los Estados Unidos: Una introducción", Doxa No 31, 2008, pp. 437-463.

Serventy-Gleeson, Molly, "Mujeres en las sombras. Un estudio sobre aborto en Chile", Independent Study Project (ISP) Collection Yale University. 
Paper 860, 2010. En: http://digitalcollections.sit.edu/cgi/viewcontent. cgi?article $=1862 \&$ context=isp_collection.

TAmayo y Salmorán, Rolando, "El sujeto de derecho", Isonomía: Revista de Teoría y Filosofía del Derecho, núm. 3, octubre 1995, pp. 167-189.

Thomson, Judith, Una defensa del aborto", VVAA. Debate sobre el aborto. Cinco ensayos de filosofía moral, Editorial Cátedra, segunda edición, 1992, pp. 9-32.

Thomson, Judith, "Derechos y muertes", VVAA. Debate sobre el aborto. Cinco ensayos de filosofía moral, Ediciones Cátedra, Madrid, 1992, pp. 143-159.

Tooley, Michael, "Aborto e infanticidio", VVAA, Debate sobre el aborto. Cinco ensayos de filosofía moral, Ediciones Cátedra, Madrid, 1992, pp. 69-107.

VEGGETI, Silvia, "El aborto, una derrota del pensamiento", Debate Feminista, año 10,Vol. 20, 1999, pp. 96-101.

WOMENS LINK WORLDWIDE, El aborto en cifras. En: http://www.womenslinkworldwide.org/pdf_programs/es_prog_rr_col_factsheets_cifras.pdf.

ZúNiga, Alejandra, "Aborto y derechos humanos", Revista de Derecho de la Universidad Austral de Chile, Vol. XXIV, N 1, 2011, pp. 163-177.

ZúÑIGA, Yanira, "Dictamen del Comité de Derechos Humanos recaído sobre la comunicación n 1153/2003 contra Perú en materia de aborto terapéutico", Revista de Derecho de la Universidad Austral de Chile, Vol. XIX №1, julio 2006, pp. 253-267. 